Article

\title{
Evaluation of the Performance of Multi-Source Precipitation Data in Southwest China
}

\author{
Xi Jiang 1,2, Yanli Liu 1,3,4 ${ }^{\mathbb{D}}$, Yongxiang Wu ${ }^{1,3, *}$, Gaoxu Wang ${ }^{1,3}$, Xuan Zhang ${ }^{1}$, Qingbo Meng ${ }^{4,5}$, Pengfei Gu ${ }^{1,6}$ \\ and Tao Liu 1,2
}

1 Institute of Hydrology and Water Resources, Nanjing Hydraulic Research Institute, Nanjing 210029, China; xjiang@nhri.cn (X.J.); ylliu@nhri.cn (Y.L.); gxwang@nhri.cn (G.W.); xzhang@nhri.cn (X.Z.); tliu@nhri.cn (T.L.); pfgu@nhri.cn (P.G.)

2 State Key Laboratory of Hydrology-Water Resources and Hydraulic Engineering, Hohai University, Nanjing 210098, China

3 Yangtze Institute for Conservation and Development, Nanjing 210098, China

4 Research Center for Climate Change of Ministry of Water Resources, Nanjing 210029, China; mengqbpersonal@gmail.com

5 Hunan Hydro \& Power Design Institute, Changsha 430100, China

6 State Key Laboratory of Hydraulics and Mountain River Engineering, Sichuan University, Chengdu 610065, China

* Correspondence: yxwu@nhri.cn

Citation: Jiang, X.; Liu, Y.; Wu, Y.; Wang, G.; Zhang, X.; Meng, Q.; Gu, P.; Liu, T. Evaluation of the Performance of Multi-Source Precipitation Data in Southwest China. Water 2021, 13, 3200. https://doi.org/10.3390/ w13223200

Academic Editor: Momcilo Markus

Received: 3 October 2021

Accepted: 8 November 2021

Published: 12 November 2021

Publisher's Note: MDPI stays neutral with regard to jurisdictional claims in published maps and institutional affiliations.

Copyright: (C) 2021 by the authors. Licensee MDPI, Basel, Switzerland. This article is an open access article distributed under the terms and conditions of the Creative Commons Attribution (CC BY) license (https:// creativecommons.org/licenses/by/ $4.0 /)$.

\begin{abstract}
The number of precipitation products at the global scale has increased rapidly, and the accuracy of these products directly affects the accuracy of hydro-meteorological simulation and forecast. Therefore, the applicability of these precipitation products should be comprehensively evaluated to improve their application in hydrometeorology. This paper evaluated the performances of six widely used precipitation products in southwest China by quantitative assessment and contingency assessment. The precipitation products were Tropical Rainfall Measuring Mission Multi-satellite Precipitation Analysis 3B42 version 7 (TRMM 3B42 V7), Global Satellite Mapping of Precipitation (GSMaP MVK), Integrated Multi-satellitE Retrievals for GPM final run (GPM IMERG Final), Precipitation Estimation from Remotely Sensed Information using Artificial Neural Network-Climate Data Record (PERSIANN-CDR), Climate Hazards Infrared Precipitation with Stations version 2.0 (CHIRPS V2.0), and the Global Land Data Assimilation System version 2.0 (GLDAS V2.0). From the above six products, the daily-scale precipitation data from 2001 to 2019 were chosen to compare with the measured data of the rain gauge, and the data from the gauges were classified by river basin and elevation. All precipitation products and measured data were evaluated by statistical indicators. Results showed that (1) GPM IMERG Final and CHIRPS V2.0 performed well in the Yarlung Zangbo River (YZ) basin, while GPM IMERG Final and GLDAS V2.0 performed well in the Lantsang River (LS), Nujiang River (NJ), Yangtze River (YT), and Yellow River (YL) basins; (2) in the upper and middle reaches of the YZ basin, GPM IMERG Final and CHIRPS V2.0 were outstanding in all evaluated products; downstream of the $\mathrm{YZ}$ basin, all six products performed well; and upstream of the LS and NJ, GPM IMERG Final, TRMM 3B42 V7, CHIRPS V2.0, and GLDAS V2.0 can be recommended as a substitute for measured data; and (3) GPM IMERG Final and GLDAS V2.0 can be seen as substitutes for measured data when elevation is below $4000 \mathrm{~m}$. GPM IMERG Final and CHIRPS V2.0 were recommended when elevation is above $4000 \mathrm{~m}$. This study provides a reference for data selection of hydro-meteorological simulation and forecast in southwest China and also provides a basis for multi-source data assimilation and fusion.
\end{abstract}

Keywords: precipitation products; southwest China; multi-source; quantitative analysis; classification analysis 


\section{Introduction}

Precipitation is one of the most important components of the water cycle [1-7]. Accuracy of the precipitation data plays a vital role in the prediction of floods, droughts [4-8], and water resource management [1,3,6-9]. Precipitation monitoring is performed in a variety of ways, such as traditional ground rain gauges, ground radar, and satellite monitoring $[10,11]$. Traditional rain gauges have high accuracy in monitoring precipitation [2], and their measured results are widely used as the true value of precipitation in many studies [12]. However, their spatial coverage is poor, and it is difficult to truly reflect the regional precipitation in sparse areas using rain gauges [9]. Ground-based radar monitoring of precipitation can accurately monitor precipitation within a range of tens to hundreds of kilometers [13]. However, due to the influence of topography, the number of radars, beam overshooting over mountainous regions, beam blockage, and bright band effects, it cannot meet the needs of scientific research [3,12-14]. Satellite monitoring of precipitation has good spatial-temporal resolution and can be used as an important supplement for ground-based monitoring of precipitation [8]. With the development of aerospace and remote sensing technology, satellite precipitation monitoring has developed rapidly $[3,5,10,12,15,16]$. A large number precipitation products have emerged (Table 1) [1-4,16-19], and they can be divided into four groups: (1) precipitation products corrected by gauge data, such as Integrated Multi-satellitE Retrievals for GPM (GPM IMERG) final, Tropical Rainfall Measuring Mission (TRMM) 3B42 V7, Rainfall Estimate (RFE), Multi-Source Weighted-Ensemble Precipitation (MSWEP), Precipitation Estimation from Remotely Sensed Information using Artificial Neural Network - Climate Data Record (PERSIANN CDR), the Global Satellite Mapping of Precipitation (GSMaP) Gauge, Climate Hazards Infrared Precipitation with Stations (CHIRPS), and the Climate Prediction Center morphing technique (CMORPH); (2) multi-source precipitation datasets, which are prepared by merging infrared (IR) estimates (high sampling frequency, indirectness, less accurate) and passive microwave (PWM) estimates (direct, accurate, roughly temporal sampling), such as GSMaP MVK, GSMaP RNL, PERSIANN, TRMM 3B42 RT, GPM IMERG Early, and GPM IMERG Late; (3) single-source precipitation datasets, which can provide precipitation products from a single satellite sensor type, such as PERSIANN CCS; and (4) reanalysis precipitation products, which are prepared by various hydrological or atmospheric models, such as Asian Precipitation-Highly-Resolved Observational Data Integration Evaluation (APHRODITE), CPC Unified Gauged Analysis of Global Daily Precipitation, and GLDAS. Although these precipitation products can be seen as a supplement for rain gauge data in sparse areas, the retrieval algorithms have pros and cons. So it is essential to analyze the performance of these products in different areas [14]. Elhamid et al. [4], who evaluated TRMM 3B43 and RFE 2.0 precipitation data in the Sudan Blue Nile sub-basin, confirmed that the two precipitation datasets have good prediction and observation ability. Sungmin et al. [20] evaluated the GPM-IMERG Early, Late, and Final precipitation products in the Wegenernet Feldbach region, southeastern Austria. It is considered that GPM-IMERG Final is most consistent with the measured data. Mohammadali and Gholam et al. [1] evaluated five precipitation products (CMORPH, PERSIANN-CDR, PERSIANN, TRMM 3B42 V7, and MSWEP in Iran), and results showed that the MSWEP reanalysis precipitation dataset has the best consistency with the measured data. With the deepening of assessment methods, increasingly more scholars have found that complex topography has an impact on satellite monitoring of precipitation [3,17,21-23]. Derin et al. [21] selected nine typical mountain areas around the world to analyze ECMWF, TRMM 3B42 V7, Tropical Rainfall Measuring Mission Multi satellite Precipitation Analysis (TMPA) CCA, and CMORPH. The results showed that the consistency of satellite precipitation data and measured data is disparate in different regions. Vidhi et al. [15] evaluated TRMM 3B42 V7 in the Himalayan region and concluded that the satellite shows good performance at an altitude of $1000-2000 \mathrm{~m}$, but there was still a large error between the precipitation monitored by the satellite and the precipitation monitored by the gauge in the region with complex topography. 
Table 1. Overview of precipitation data products mentioned in the Introduction section.

\begin{tabular}{|c|c|c|c|c|c|}
\hline $\begin{array}{l}\text { Precipitation } \\
\text { Products }\end{array}$ & $\begin{array}{c}\text { Spatial } \\
\text { Resolution }\end{array}$ & $\begin{array}{l}\text { Spatial } \\
\text { Range }\end{array}$ & $\begin{array}{l}\text { Temporal } \\
\text { Resolution }\end{array}$ & Time Period & Download \\
\hline TRMM 3B42 & $0.25^{\circ}$ & $50^{\circ} \mathrm{N}-50^{\circ} \mathrm{S}$ & 3 h/Daily & 1998-2019 & $\begin{array}{c}\text { https://disc.gsfc.nasa.gov (accessed on } 5 \\
\text { November 2021) }\end{array}$ \\
\hline TRMM 3B43 & $0.25^{\circ}$ & $40^{\circ} \mathrm{N}-40^{\circ} \mathrm{S}$ & Monthly & 1998-2019 & https:// disc.gsfc.nasa.gov (accessed on 5 \\
\hline TMPART & $0.25^{\circ}$ & $50^{\circ} \mathrm{N}-50^{\circ} \mathrm{S}$ & Daily & 1998-2019 & $\begin{array}{c}\text { https: / / disc.gsfc.nasa.gov (accessed on } 5 \\
\text { November 2021) }\end{array}$ \\
\hline $\begin{array}{l}\text { GPM-IMERG } \\
\text { Early/Late/Final }\end{array}$ & $0.1^{\circ}$ & $90^{\circ} \mathrm{N}-90^{\circ} \mathrm{S}$ & 0.5 h/Daily/Monthly & 2015-now & $\begin{array}{l}\text { https: / / gpm.nasa.gov / data / directory } \\
\text { (accessed on } 7 \text { November 2021) }\end{array}$ \\
\hline GSMaP MVK & $0.1^{\circ}$ & $60^{\circ} \mathrm{N}-60^{\circ} \mathrm{S}$ & 1 h/Daily/Monthly & 1998-now & $\begin{array}{l}\text { ftp:/ / sharaku.eorc.jaxa.jp/GSMaP / } \\
\text { index.html (accessed on } 6 \text { August 2021) }\end{array}$ \\
\hline GSMaP RNL & $0.1^{\circ}$ & $60^{\circ} \mathrm{N}-60^{\circ} \mathrm{S}$ & $1 \mathrm{~h} /$ Daily/Monthly & 1998-now & $\begin{array}{l}\text { ftp:/ / sharaku.eorc.jaxa.jp/GSMaP/ } \\
\text { index.html (accessed on } 6 \text { August 2021) }\end{array}$ \\
\hline GSMaP Gauge & $0.1^{\circ}$ & $60^{\circ} \mathrm{N}-60^{\circ} \mathrm{S}$ & $1 \mathrm{~h} /$ Daily/Monthly & 1998-now & $\begin{array}{l}\text { ftp:/ / sharaku.eorc.jaxa.jp /GSMaP / } \\
\text { index.html (accessed on } 6 \text { August 2021) }\end{array}$ \\
\hline PERSIANN-CDR & $0.25^{\circ}$ & $60^{\circ} \mathrm{N}-60^{\circ} \mathrm{S}$ & 3 h/Daily & 1983-now & $\begin{array}{c}\text { https:/ / www.ncdc.noaa.gov (accessed on } \\
7 \text { November 2021) }\end{array}$ \\
\hline PERSIANN & $0.25^{\circ}$ & $60^{\circ} \mathrm{N}-60^{\circ} \mathrm{S}$ & $0.5 \mathrm{~h} /$ Daily & 1983-now & $\begin{array}{c}\text { https:/ / www.ncdc.noaa.gov (accessed on } \\
7 \text { November 2021) }\end{array}$ \\
\hline PERSIANN-CCS & $0.25^{\circ}$ & $60^{\circ} \mathrm{N}-60^{\circ} \mathrm{S}$ & 0.5 h/Daily & 1983-now & $\begin{array}{c}\text { https://www.ncdc.noaa.gov (accessed on } \\
7 \text { November 2021) }\end{array}$ \\
\hline CMORPH-CRT & $8 \mathrm{~km}$ & $60^{\circ} \mathrm{N}-60^{\circ} \mathrm{S}$ & $0.5 \mathrm{~h}$ & 2002-now & $\begin{array}{c}\text { https:/ / www.cpc.ncep.noaa.gov / } \\
\text { (accessed on } 25 \text { August 2021) }\end{array}$ \\
\hline CMORPH-BLD & $0.25^{\circ}$ & $60^{\circ} \mathrm{N}-60^{\circ} \mathrm{S}$ & $3 \mathrm{~h}$ & 2002-now & $\begin{array}{l}\text { https: / / www.cpc.ncep.noaa.gov / } \\
\text { (accessed on } 25 \text { August 2021) }\end{array}$ \\
\hline MSWEP & $0.1^{\circ} / 0.25^{\circ}$ & Global & 3 h/Daily & 1979-now & $\begin{array}{c}\text { http:// www.gloh2o.org (accessed on } 3 \\
\text { November 2021) }\end{array}$ \\
\hline CHIRPS & $0.05^{\circ} / 0.25^{\circ}$ & $60^{\circ} \mathrm{S}-60^{\circ} \mathrm{N}$ & Daily & 1981-now & $\begin{array}{l}\text { https: / / www.chc.ucsb.edu/data/chirps } \\
\text { (accessed on } 3 \text { November 2021) }\end{array}$ \\
\hline NCEP-CFSR & $38 \mathrm{~km}$ & Global & Daily & 1979-now & $\begin{array}{l}\text { https:/ / hycom.org/ dataserver/ncep-cfsr } \\
\text { (accessed on } 12 \text { September 2021) }\end{array}$ \\
\hline NCEP-NCAR & $2.5^{\circ}$ & Global & Daily/Monthly & 1948-now & $\begin{array}{c}\text { https:/ / www.globalchange.gov (accessed } \\
\text { on } 12 \text { September 2021) }\end{array}$ \\
\hline GLDAS & $0.25^{\circ}$ & $80^{\circ} \mathrm{N}-50^{\circ} \mathrm{S}$ & 3 h/Daily/Monthly & 2000-now & $\begin{array}{c}\text { https: / / disc.gsfc.nasa.gov (accessed on } 5 \\
\text { November 2021) }\end{array}$ \\
\hline ERA & $1.5^{\circ} / 0.75^{\circ}$ & Global & $6 \mathrm{~h} /$ Monthly & 1979-now & $\begin{array}{l}\text { https://cds.climate.copernicus.eu } \\
\text { (accessed on } 8 \text { October 2021) }\end{array}$ \\
\hline APHRODITE & $0.25^{\circ}$ & $\begin{array}{l}\text { East Asian } \\
\text { region }\end{array}$ & Daily & 1951-2017 & $\begin{array}{l}\text { http: / / aphrodite.st.hirosaki-u.ac.jp/ } \\
\text { download/ (accessed on } 8 \text { October 2021) }\end{array}$ \\
\hline REF & $10 \mathrm{~km}$ & South Asia & Daily & 2000-now & $\begin{array}{c}\text { https: / / ftp.cpc.ncep.noaa.gov / fews/S. } \\
\text { Asia/data (accessed on } 8 \text { October 2021) } \\
\text { https: }\end{array}$ \\
\hline CRU TS & $0.5^{\circ}$ & Global & Monthly & 1901-2015 & $\begin{array}{l}\text { //crudata.uea.ac.uk/cru/data/precip/ } \\
\text { (accessed on } 8 \text { October 2021) }\end{array}$ \\
\hline ECMWF & $0.5^{\circ}$ & Global & Daily & 1979-now & $\begin{array}{l}\text { https: / / cds.climate.copernicus.eu } \\
\text { (accessed on } 8 \text { October 2021) }\end{array}$ \\
\hline $\mathrm{CPC}$ & $0.5^{\circ}$ & global land & Daily & 1979-2005 & $\begin{array}{c}\mathrm{ftp}: / / \text { ftp.cpc.ncep.noaa.gov (accessed on } \\
8 \text { October 2021) }\end{array}$ \\
\hline
\end{tabular}

The southwest of China is the source of many rivers (Yarlung Zangbo River (YZ), Lantsang River (LS), Nujiang River (NJ), Yangtze River (YT), and Yellow River (YL)) located in the Tibetan Plateau (TP) and the Yunnan-Kweichow Plateau (YKP), where the terrain and topography are complex. It is a typical area lacking in hydrometeorological measurements [17]. In recent years, increasingly more studies have focused their attention on the southwest of China $[2,17,23]$. Xu et al. [23] evaluated the applicability of GPM IMERG Final and TRMM 3B 42V7 in southern TP and analyzed the performance of satellite rainfall products with topography. They found that GPM IMERG Final has better performance in the southern TP region. At the same time, they also found that there is nearly no detection skill for both GPM and TRMM at high-elevation ( $>4500 \mathrm{~m}$ ) regions. Ma et al. [2] evaluated the GPM IMERG satellite precipitation data from 2014 to 2017 over the Tibetan Plateau and concluded that the GPM IMERG performs better at $3000 \mathrm{~m}-4000 \mathrm{~m}$. Gao et al. [17] evaluated data from four satellites, TMPA 3B42 version 6, CMORPH, PERSIANN, and TMPA Real Time version (TMPART), from 2004 to 2009 in the TP and found that the bias of TMPA and CMORPH is less dependent on topography. However, the bias of TMPART and PERSIANN was strongly dependent on topography. 
Now, the evaluation of satellite precipitation data in southwest China was mainly aimed at the TP or only one basin $[2,12,17]$. Previous assessments on the accuracy of precipitation products often had short assessment time series and insufficient assessment data products. However, actual hydrological simulations and water resource research mostly require long series of precipitation data. So, it is significant for hydrology research to analyze the applicability of various precipitation datasets.

Our study focused on all basins (YZ, LS, NJ, YT, and YL) in southwest China to evaluate the precipitation datasets (TRMM 3B42 V7, GSMAP-MVK, GPM IMERG Final, PERSIANN-CDR, GLDAS V2.0, and CHIRPS V2.0) for 20 years (2001-2019). It is hoped that this study can provide a scientific reference for hydro-meteorological applications of precipitation datasets in southwest China.

\section{Materials and Methods}

\subsection{Study Area}

In our study, we focused on southwest China, including Xizang, Gansu, Sichuan, and Yunnan Provinces; we mainly focused on the area of $21-37^{\circ} \mathrm{N}$ and $80-104^{\circ} \mathrm{E}$, which is rich in water resources. It is the source of many major rivers in Asia (YZ, LS, NJ, YT, and YL). The basic information about the five catchments is given in Table 2. It is an irreplaceable water storage area in China and is considered to be one of the most active water-cycling regions in the world [24,25]. Our study area was mainly located in the TP, and a small part was located in the YKP. Terrain and topography play an important role in precipitation monitoring; there is nearly an $85 \%$ area above $3000 \mathrm{~m}$ elevation, the installation and maintenance of rain gauges in which is difficult, so it is a typical region that lacks measured data [26]. Satellite precipitation products make up for the scarcity of measured data, but there is a large error in the alpine cold region. The evaluation of precipitation products in southwest China can provide scientific reference for decision making about water planning and management and flood and drought disaster prediction.

Table 2. Distribution of rain gauge stations in five basins of southwest China.

\begin{tabular}{|c|c|c|c|c|c|c|}
\hline $\begin{array}{l}\text { Basin } \\
\text { Name }\end{array}$ & $\begin{array}{l}\text { Number of } \\
\text { Rain Gauges }\end{array}$ & $\begin{array}{c}\text { Average } \\
\text { Altitude (m) }\end{array}$ & $\begin{array}{c}\text { Altitude } \\
\text { Change (m) }\end{array}$ & $\begin{array}{c}\text { Basin Area } \\
\left(10,000 \mathrm{~km}^{2}\right)\end{array}$ & $\begin{array}{c}\text { Rain Gauge } \\
\text { Network Density } \\
(\text { Pcs/10,000 km²) }\end{array}$ & Spatial Range \\
\hline$Y Z$ & 27 & 4625 & 8622 & 38.58 & 0.70 & $\begin{array}{l}31.28-27.99 \\
81.99-97.10\end{array}$ \\
\hline LS & 29 & 3104 & 5996 & 16.52 & 1.76 & $\begin{array}{c}33.82-21.14 \\
93.86-101.84\end{array}$ \\
\hline $\mathrm{NJ}$ & 15 & 4026 & 6465 & 13.49 & 1.11 & $\begin{array}{c}32.77-22.09 \\
91.14-100.23\end{array}$ \\
\hline $\mathrm{YT}$ & 15 & 4443 & 5273 & 32.67 & 0.46 & $\begin{array}{c}35.90-27.62 \\
90.54-102.29\end{array}$ \\
\hline YL & 30 & 3869 & 6320 & 25.38 & 1.18 & $\begin{array}{c}36.97-28.81 \\
95.89-103.94\end{array}$ \\
\hline
\end{tabular}

\subsection{Data}

\subsubsection{Rain Gauge Data}

The data measured by rain gauges were downloaded from the Resources and Environment Science and Data Center (RESDC; https:/ / www.resdc.cn/, accessed on 1 November 2021), and a strict quality control step was executed to avoid errors. We used daily precipitation records of 116 rain gauges from 1 January 2001 to 31 December 2019. Figure 1 shows the locations of rain gauges in our study, and it can be clearly seen that the distribution of the rain gauges was uneven and the density of the rain gauge network obviously decreased with an increase in elevation. The rain gauges were located at altitudes ranging from $556 \mathrm{~m}$ to $5339 \mathrm{~m}$, and $78.4 \%$ of them were located below $4000 \mathrm{~m}$ (Figure 1). These rain gauge observations were used as the true value when evaluating the grid precipitation 
products. To make the results more representative, rain gauges near the study area were considered in our study; these rain gauges were divided into different basins according to the nearest proximity.

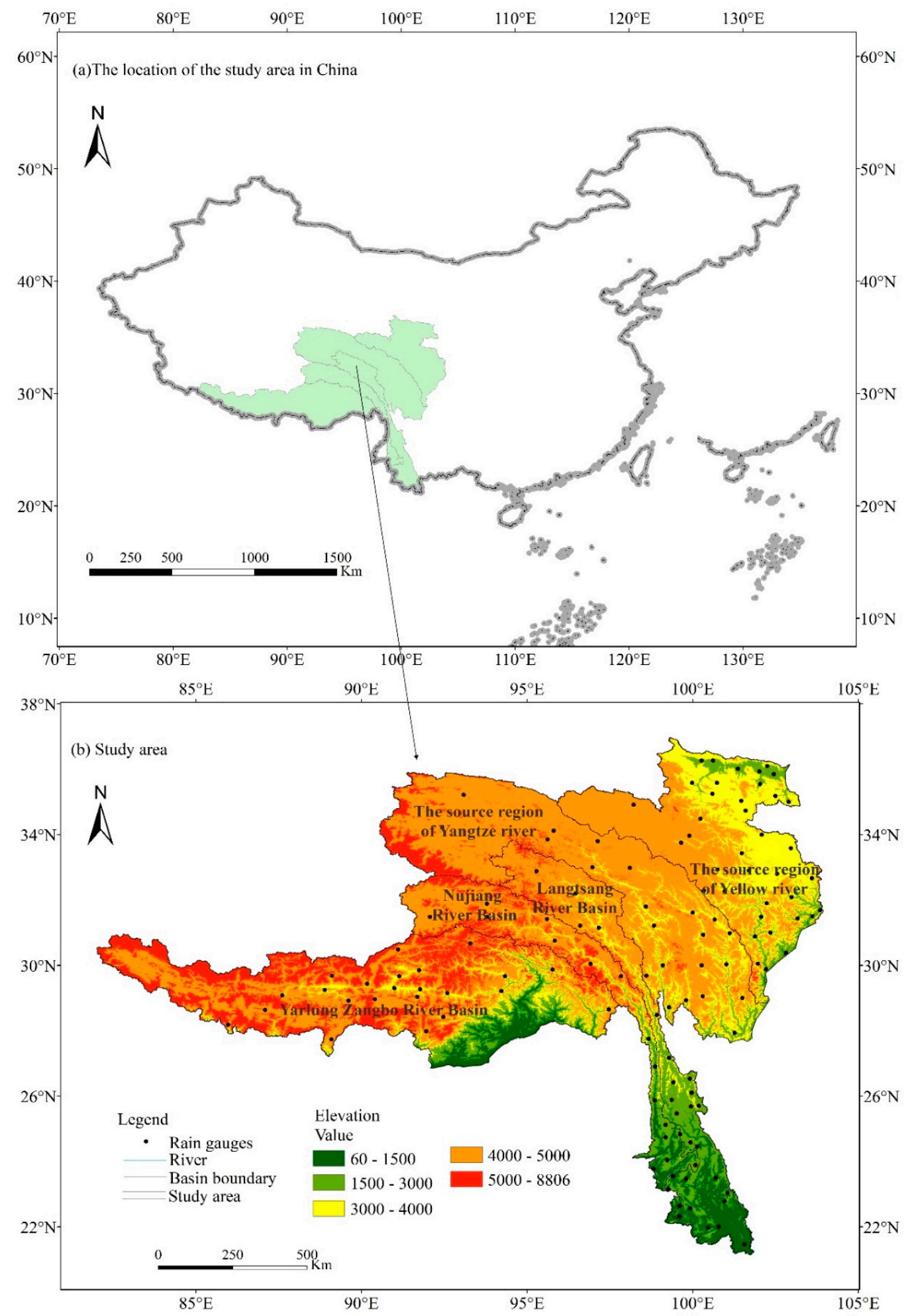

Figure 1. Overview of the study area (Figure (a) mainly expresses the geographic location of the study area in China; Figure (b) shows the detail information of the study area). 


\subsubsection{Precipitation Products}

Our study involved six types of satellite precipitation products, including four precipitation datasets corrected by gauge data (TRMM 3B42 V7, GPM IMERG Final, PERSIANNCDR, and CHIRPS V2.0); one multi-source precipitation dataset (GSMaP MVK); and one reanalysis product (GLDAS V2.0). It is worth noting that PERSIANN-CDR and CHIRPS V2.0 are both single source from infrared (IR) estimates and TRMM 3B42 V7 and GPM IMERG Final are both multi-source from IR estimates and PMW estimates. GSMAP MVK and GPM IMERG Final are two representative products of GPM satellites and are considered as the next-generation products of TRMM. The detailed information about the six precipitation products is shown in Table $3[17,27]$. We summarize the generated algorithms for the six precipitation products as follows:

Table 3. Basic information about the six precipitation products selected in this study.

\begin{tabular}{|c|c|c|c|c|c|}
\hline Rainfall Product & $\begin{array}{c}\text { Temporal } \\
\text { Resolution }\end{array}$ & $\begin{array}{c}\text { Spatial } \\
\text { Resolution }\end{array}$ & Space Coverage & $\begin{array}{c}\text { Select Time Series } \\
\text { in the Study }\end{array}$ & References \\
\hline TRMM 3B42 V7 & $1 \mathrm{~d}$ & $0.25^{\circ} \times 0.25^{\circ}$ & $50^{\circ} \mathrm{S}-50^{\circ} \mathrm{N}$ & $\begin{array}{l}1 \text { January } 2001 \text { to } \\
31 \text { December } 2019\end{array}$ & {$[6,7,10]$} \\
\hline GSMAP MVK & $1 \mathrm{~d}$ & $0.1^{\circ} \times 0.1^{\circ}$ & $60^{\circ} \mathrm{S}-60^{\circ} \mathrm{N}$ & $\begin{array}{c}1 \text { January } 2001 \text { to } \\
31 \text { December } 20101 \\
\text { March } 2014 \text { to } 31 \\
\text { December } 2019\end{array}$ & [27-29] \\
\hline GPM IMERG Final & $1 \mathrm{~d}$ & $0.1^{\circ} \times 0.1^{\circ}$ & $60^{\circ} \mathrm{S}-60^{\circ} \mathrm{N}$ & $\begin{array}{l}1 \text { March } 2014 \text { to } 31 \\
\text { December } 2019\end{array}$ & {$[19,30]$} \\
\hline PERSIANN-CDR & $1 \mathrm{~d}$ & $0.25^{\circ} \times 0.25^{\circ}$ & $60^{\circ} \mathrm{S}-60^{\circ} \mathrm{N}$ & $\begin{array}{l}1 \text { January } 2001 \text { to } \\
31 \text { December } 2019\end{array}$ & {$[31,32]$} \\
\hline CHIRPS V2.0 & $1 \mathrm{~d}$ & $0.25^{\circ} \times 0.25^{\circ}$ & $50^{\circ} \mathrm{S}-50^{\circ} \mathrm{N}$ & $\begin{array}{l}1 \text { January } 2001 \text { to } \\
31 \text { December } 2019\end{array}$ & {$[15,33,34]$} \\
\hline GLDAS V2.0 & $1 \mathrm{~d}$ & $0.25^{\circ} \times 0.25^{\circ}$ & $90^{\circ} \mathrm{S}-60^{\circ} \mathrm{N}$ & $\begin{array}{l}1 \text { January } 2001 \text { to } \\
31 \text { December } 2014\end{array}$ & {$[35,36]$} \\
\hline
\end{tabular}

TRMM 3B42 V7 (https://disc.gsfc.nasa.gov/datasets/, accessed on 5 November 2021) was generated by the $3 \mathrm{~h}$ TRMM multi-satellite precipitation analysis TMPA (3B42), calibrated microwave (MW) precipitation estimates, which were further combined with infrared (IR) estimates and then corrected by monthly Global Precipitation Climatology Centre (GPCC) gauge data $[6,8,11]$.

The GSMAP-MVK (ftp:/ / sharaku.eorc.jaxa.jp, accessed on 6 August 2021) project used multi-sensor observations as input to retrieve precipitation rates and was called MW-IR Combined Product. The main feature of the GSMAP algorithm is the use of various attributes derived from space-borne precipitation radars, such as the TRMM Precipitation Radar (PR) and GPM Core Observatory Dual-frequency Precipitation Radar (DPR) [27-29].

GPM IMERG Final (https:/ /gpm.nasa.gov/data/directory, accessed on 7 November 2021) makes full use of the data provided by other satellite sensors on the GPM platform (including active and passive microwave sensors and all kinds of infrared data sensors, such as the GMI and DPR) and also makes full use of other kinds of satellite precipitation inversion algorithms in the TRMM era, such as PERSIANN-CCS and CMORPH-style [20,30].

PERSIANN-CDR (https:/ / www.ncdc.noaa.gov, accessed on 7 November 2021) produced by the technique of artificial neural network inversion imaging is obtained by remote sensing observation IR precipitation. The monthly Global Precipitation Climatology Project (GPCP) precipitation data are used to correct PERSIANN rainfall estimates, and then, those bias correct estimates are accumulated to obtain daily figures [31,32].

CHIRPS V2.0 (https://www.chc.ucsb.edu/data/chirps, accessed on 3 November 2021) is a 35+ year quasi-global rainfall product, developed on IR estimates, corrected by 5-day gauge data $[16,33,34]$. 
GLDAS V2.0 (https:/ / disc.gsfc.nasa.gov, accessed on 5 November 2021) uses land surface modeling (Noah model, catchment model, VIC model, etc.) and data assimilation techniques to generate satellite and gauge-based products [35-37].

\subsubsection{Climate Spatial Distribution Data}

We choose the Global Köppen climate-type spatial distribution dataset (http:/ / www. geodata.cn/data/datadetails.html, accessed on 5 November 2021) to finish the climate classification. The dataset obtained based on the relationship between climate and vegetation was used to reflect the geographical distribution of long-term climate and ecosystems. According to this dataset, we completed the climatic division of the study area (Figure 2, Table 4). In Figure 2, the first letter, " $A$ " represents tropical, " $B$ " represents dry, " $C$ " represents mild temperate, " $\mathrm{D}$ " represents snow, and " $\mathrm{E}$ " represents polar; the meaning of the second letter and the third letter can be found at koppen_all_1901-2010.png $(3200 \times 2400)$ (hanschen.org) [38,39].

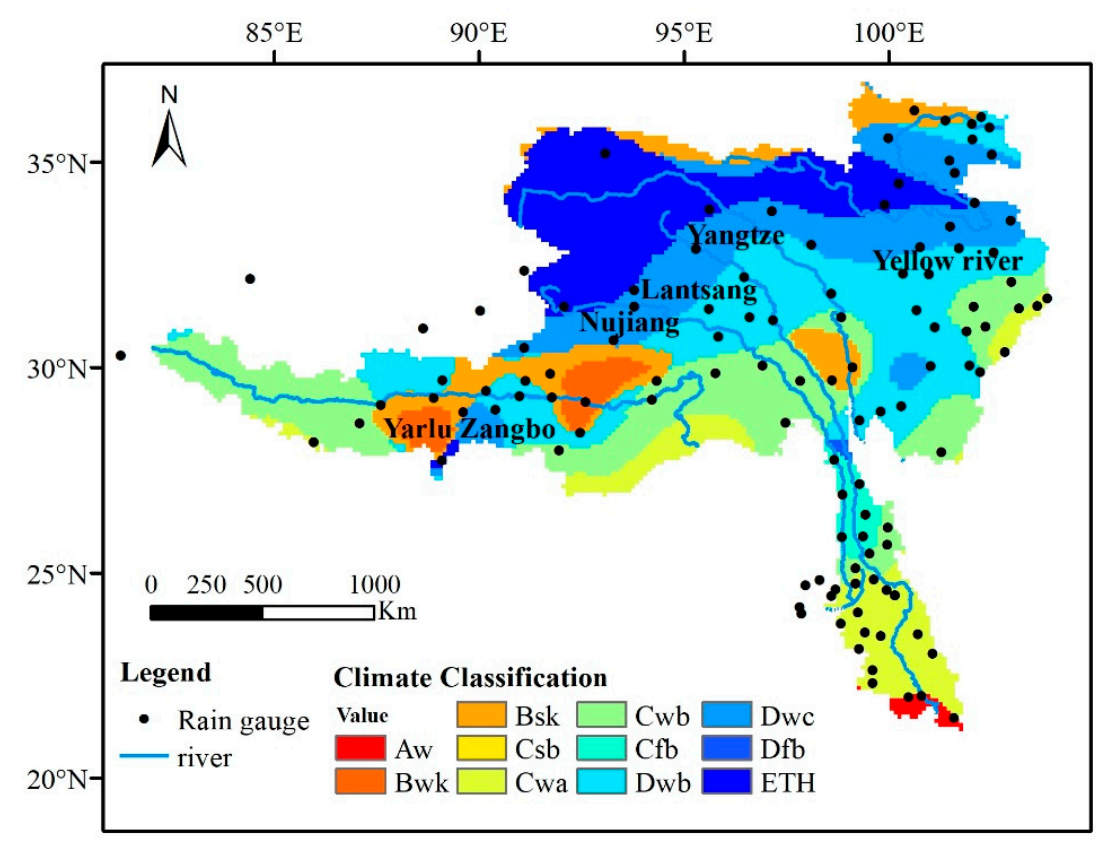

Figure 2. Climate division of southwest China.

Table 4. Climate divisions in the five main river basins of southwest China.

\begin{tabular}{cccccccccccc}
\hline Basin Name & Aw & Bwk & Bsk & Csb & Cwa & Cwb & Cfb & Dwb & Dwc & Dfb & ETH \\
\hline YZ & $/$ & 9 & 14 & $/$ & 9 & 42 & $/$ & 18 & 7 & $/$ & 1 \\
LS & 4.42 & $/$ & 3.94 & 0.07 & 30.02 & 10.69 & 8.18 & 24.30 & 13.75 & 0.82 & 3.81 \\
NJ & $/$ & $/$ & $/$ & $/$ & 12 & 20 & 6 & 16 & 21 & $/$ & 25 \\
YT & $/$ & $/$ & 6.69 & $/$ & 0.03 & 10.22 & $/$ & 30.59 & 14.09 & $/$ & 38.38 \\
YR & $/$ & $/$ & 8.98 & $/$ & 3.46 & 11.99 & $/$ & 22.55 & 31.83 & $/$ & 21.19 \\
\hline
\end{tabular}

In the above table, the number represents the ratio of the corresponding climate zone to the total area of the basin (\%).

\subsection{Methods}

\subsubsection{Evaluation Statistics}

Four statistical indicators (correlation coefficient (CC), bias, root-mean-square error (RMSE), and mean absolute error (MAE)) were used to quantitatively analyze the accuracy of the six products [40]. The CC represents the agreement of gauge datasets and precipitation products. Bias represents system errors, meaning the degree of overestimation or underestimation of the rainfall products. The RMSE and MAE were used to describe the 
error between rainfall product data and ground measured data, and they represent the accuracy of the data [5]., We also used three contingency table statistics (probability of detection (POD), false alarm ration (FAR), and critical success index (CSI)) to describe the ability of the precipitation products to monitor the occurrence of precipitation events. The POD means the ratio of rain occurrences correctly measured to the total number of observed events; the FAR means false alarm times in the total number of observed events; and the CSI means the proportion correct for the quantity being forecast, after removing correct "no" forecasts from consideration. In this paper, the threshold for determining the occurrence of precipitation was $0.1 \mathrm{~mm} /$ day [22]. It is worth noting that the optimal value of the three indicators the CC, POD, and CSI was 1, while the optimal value of the bias, RMSE, MAE, and FAR was 0 [41].

$$
\begin{gathered}
C C=\frac{\sum_{1}^{n}\left(A_{i}-\bar{A}\right)\left(B_{i}-\bar{B}\right)}{\sqrt{\sum_{1}^{n}\left(A_{i}-\bar{A}\right)^{2} \cdot \sum_{1}^{n}\left(B_{i}-\bar{B}\right)^{2}}} \\
\text { Bias }=\frac{\sum_{i=1}^{n}\left(A_{i}-B_{i}\right)}{\sum_{i=1}^{n} B_{i}} \\
\text { RMSE }=\sqrt{\frac{\sum_{i=1}^{n}\left(A_{i}-B_{i}\right)^{2}}{n}} \\
\text { MAE }=\frac{1}{n} \sum_{i=1}^{n}\left|B_{i}-A_{i}\right| \\
\text { POD }=\frac{T}{T+M} \\
\text { FAR }=\frac{F}{T+F} \\
\text { CSI }=\frac{T}{T+M+F}
\end{gathered}
$$

In the formula, $\mathrm{n}$ represents the total number of rainfall estimates, Ai represents the precipitation product estimates $(\mathrm{mm}), \overline{\mathrm{A}}$ represents the average of precipitation product estimates $(\mathrm{mm})$, and $B$ and $\bar{B}$ represent gauge-measured values $(\mathrm{mm})$ and their average, respectively. T represents the number of precipitation events correctly monitored by the precipitation satellite, F represents the number that no precipitation event occurred but the rainfall product misjudged it as a precipitation event, and $\mathrm{M}$ represents the actual occurrence of precipitation events but the rainfall product failed to detect it (Table 5).

Table 5. Contingency table for satellite products.

\begin{tabular}{cccc}
\hline \multirow{2}{*}{ Rainfall product } & \multicolumn{2}{c}{ Rain Gauge } \\
\cline { 3 - 4 } & Occur & Occur & Not Occur \\
\hline \multirow{2}{*}{ Not occur } & $\mathrm{T}$ & $\mathrm{F}$ \\
& M & 0 \\
\hline
\end{tabular}

\subsubsection{Evaluation Methodology}

In our study, we chose data from 2001 to 2019 to analyze the performance of six precipitation products (GPM IMERG Final, TRMM 3B42 V7, GPM MVK, PERSIANNCDR, CHIRPS V2.0, GLDAS V2.0). All products were evaluated with rain gauge data downloaded from the RESDC; all gauge data executed a strict quality control step to avoid errors [42], and we used the nearest-neighbor method to extract the products' values into points, which matched rain gauges. All products were interpolated at $0.1^{\circ}$ grid cells by the nearest-neighbor method with Python, and all grid cells with no overlapping gauges were excluded in this study; we transformed all precipitation products with universal 
time coordinated (UTC) to local standard time (LST) to be consistent with rain gauges. Evaluation was performed by creating pairs of the average rain gauge rainfall values and the precipitation products over the study area. All evaluations were calculated at a daily scale.

\section{Results and Discussion}

\subsection{Applicability Analysis of Satellite Precipitation Data and Measured Data in Different} River Basins

\subsubsection{Quantitative Analysis at the Basin Scale}

In the YZ basin (Figure 3), GPM IMERG Final and CHIRPS V2.0 performed better, with a larger $\mathrm{CC}\left(\mathrm{CC}_{\mathrm{GPM} \text { IMERG Final }}=0.769 ; \mathrm{CC}_{\mathrm{CHIRPS} \text { v2.0 }}=0.692\right)$ and a smaller bias $\left(\right.$ bias $_{\text {GPM IMERG Final }}=0.184$; bias $\left._{\text {CHIRPS v2 } \cdot 0}=0.092\right)$, RMSE $\left(\right.$ RMSE $_{\text {GPM IMERG Final }}=1.450$; RMSE $\left._{\text {CHIRPS v } 2 \cdot 0}=1.700\right)$, and MAE (MAE GPM IMERG Final $=0.850 ;$ MAE $\left._{\text {CHIRPS v2 } \cdot 0}=0.940\right)$. Except for GSMAP MVK (CC $=0.493)$, the correlation of the other five precipitation products in the $Y Z$ basin was fine (CC > 0.657), and the systematic error of GLDAS V2.0 and PERSIANN-CDR in the YZ basin was large, with bias higher than 0.7. GLDAS V2.0 and PERSIANN-CDR did not perform as well as the other four products in the RMSE and MAE.
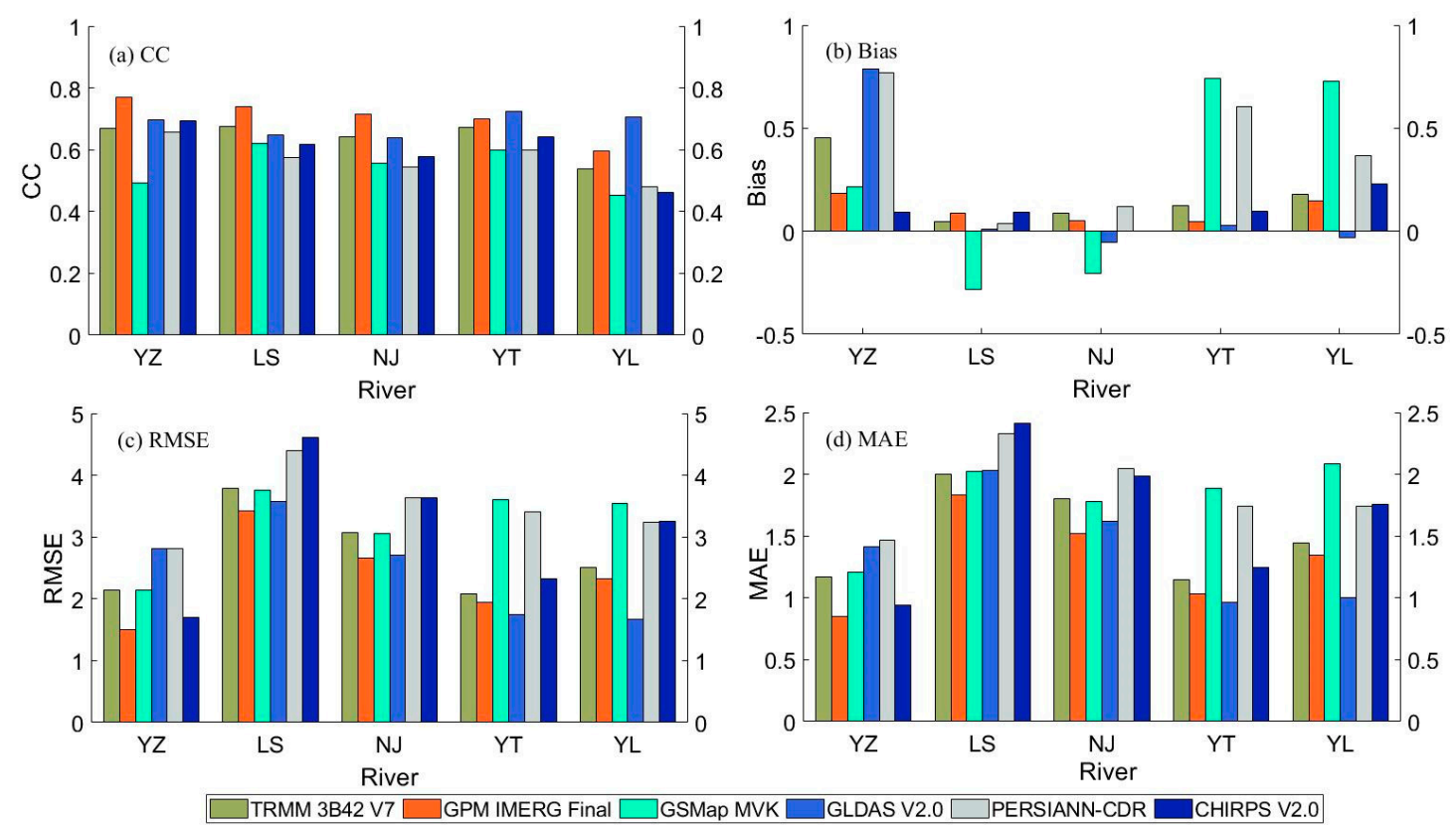

Figure 3. Quantitative analysis results of six satellite precipitation products in five river basins, (a) a represents the CC value of six products on each basin; (b) a represents the Bias value of six products on each basin; (c) a represents the RMSE value of six products on each basin; (d) a represents the MAE value of six products on each basin.

In the LS basin (Figure 3), GPM IMERG Final performed better as well, and GLDAS V2.0 also performed well, with a larger CC $\left(\mathrm{CC}_{\mathrm{GPM} \text { IMERG Final }}=0.741 ; \mathrm{CC}_{\mathrm{GLDAS} \mathrm{V} 2 \cdot 0}\right.$ $=0.647$ ) and a smaller vias ( bias $_{\mathrm{GPM} \text { IMERG Final }}=0.088$; $\left.\operatorname{bias}_{\mathrm{GLDAS} \mathrm{V} 2 \cdot 0}=0.010\right)$, $\mathrm{RMSE}$ $\left(\right.$ RMSE $_{\text {GPM IMERG Final }}=3.421 ;$ RMSE $\left._{\text {GLDAS V2 } \cdot 0}=3.572\right)$, and MAE $\left(\right.$ MAE $_{\text {GPM IMERG Final }}=$ 1.832; MAE GLDAS V2.0 $=2.032$ ). With regard to the CC, except PERSIANN-CDR, whose $\mathrm{CC}=0.575$; the rest of them all had CC above 0.6 , showing significant correlation. The bias of GSMAP MVK in the LS basin was the highest (bias $=-0.284$ ). The error between precipitation products and rain gauge data of PERSIANN-CDR and CHIRPS V2.0 in the LS basin was significantly higher than that of the other precipitation products (RMSE PERSIANN-CDR $=4.392 ; \mathrm{RMSE}_{\mathrm{CHIRPS} \mathrm{V}} \cdot 0=4.619 ; \mathrm{MAE}_{\mathrm{PERSIANN}-\mathrm{CDR}}=2.329 ; \mathrm{MAE}_{\mathrm{CHIRPS} \text { V2 } \cdot 0}=2.410$ ).

In the $\mathrm{NJ}$ basin (Figure 3), the performance of each precipitation product was similar to that in the LS basin. GPM IMERG Final and GLDAS V2.0 performed better. Except GPM 
IMERG Final, whose $C C=0.716$, the rest of other precipitation products showed similar correlations, fluctuating around 0.6, and the bias of GSMAP MVK in the NJ basin was the largest (bias $=-0.203$ ). PERSIANN-CDR and CHIRPS V2.0 in the NJ basin had a significant error between precipitation products and rain-gauge-measured data (RMSE PERSIANN-CDR $_{\text {S }}$ $=3.630 ; \mathrm{RMSE}_{\mathrm{CHIRPS} V 2 \cdot 0}=3.632 ; \mathrm{MAE}_{\text {PERSIANN-CDR }}=2.049 ; \mathrm{MAE}_{\mathrm{CHIRPS} \text { V2 } \cdot 0}=1.987$ ).

In the YT basin (Figure 3$)$, due to a higher CC $\left(\mathrm{CC}_{\mathrm{GPM}}\right.$ IMERG Final $=0.700 ; \mathrm{CC}_{\mathrm{GLDAS}} \mathrm{V} \cdot 0$ $=0.723)$ and lower bias $\left(\right.$ bias $_{\mathrm{GPM}}$ IMERG Final $=0.047$; bias $\left._{\mathrm{GLDAS} V 2 \cdot 0}=0.026\right)$, RMSE $\left(\right.$ RMSE $_{\text {GPM IMERG Final }}=1.950 ;$ RMSE $\left._{\text {GLDAS }}=1.745\right)$, and MAE $\left(\mathrm{MAE}_{\mathrm{GPM}}\right.$ IMERG Final $=$ 1.034; $\left.\mathrm{MAE}_{\mathrm{GLDAS}}=0.964\right)$, GPM IMERG Final and GLDAS V2.0 stood out among all the precipitation products. All products showed good correlation, fluctuating around 0.6. GSMAP MVK and PERSIANN-CDR performed poorly on bias, with bias higher than 0.6. Similarly, GSMAP MVK and PERSIANN-CDR did not perform as well as the other four products on the RMSE and MAE.

In the YL basin (Figure 3), all products performed poorly on the CC, except GLDAS V2.0 (CC = 0.705) and GPM IMERG Final (CC = 0.597). GSMAP MVK and PERSIANN-CDR did not perform as well as others on the bias, RMSE, and MAE.

In all five basins, GPM IMERG Final showed better performance. This conclusion was consistent with [2] and [23]. Mainly because the sensor carried by the GPM satellite is superior to those of other satellites, such as the GMI and DPR, and can provide more accurate estimation for light rainfall and snow [32], compared to GSMaP MVK, GPM IMERG Final data had been corrected by gauge data [20]. On the contrary, GPM IMERG Final, as the next generation of TRMM 3B42 V7, showed improved performance on all quantitative indicators selected in our study [5]. Chen et al. put forward a consistent view in their paper [5]. The performance of GLDAS V2.0 in LS, NJ, YT, and YL basins was all better, mainly because the re-analysis data, to some extent, made up for the lack of satellite monitoring data through the calculation of the surface model. GSMAP MVK mainly showed a higher bias in NJ, LS, YT, and YL basins, which may be due to the lack of rain gauge data correction. The main reason for the poor performance of PERSIANN-CDR was that it is based only on the IR sensor, which indirectly calculates precipitation by cloud-top temperature. The IR sensor is far less effective than the MW sensor in monitoring weak precipitation and small water droplets [30]. Another interesting aspect found was that the values of RMSE and MAE in YZ, YT, and YL basins were smaller, while those in the LS and NJ basins were higher. This was mainly because the lower reaches of LS and NJ are located in the YKP and the intensity of precipitation is higher here.

\subsubsection{Classification Analysis at the Basin Scale}

The performance of the three contingency indicators in our study was good (Figure 4). The POD was higher than 0.72, FAR was less than 0.3, and the CSI was higher than 0.67 . Therefore, we believe that the six products can accurately monitor the occurrence of precipitation events.

In the five river basins, we could clearly see that the six products on the LS (the largest value of FAR was 0.209 , and in the following paragraphs, FARmax is used to represent the maximum value of FAR) and NJ (FARmax $=0.205$ ) basins performed significantly better than on the other three river basins, the main reason being that most rain gauges in LS and $\mathrm{NJ}$ are distributed in temperate regions and areas with a lower mean altitude, so it is beneficial to distinguish precipitation events by IR, MW, and other sensors. $Y Z$ is located at a higher average altitude, which brings difficulties for satellite monitoring. For YT and YL, temperate regions account for a smaller proportion of the total area, mostly snow-covered areas, which is not conducive to satellite monitoring. 

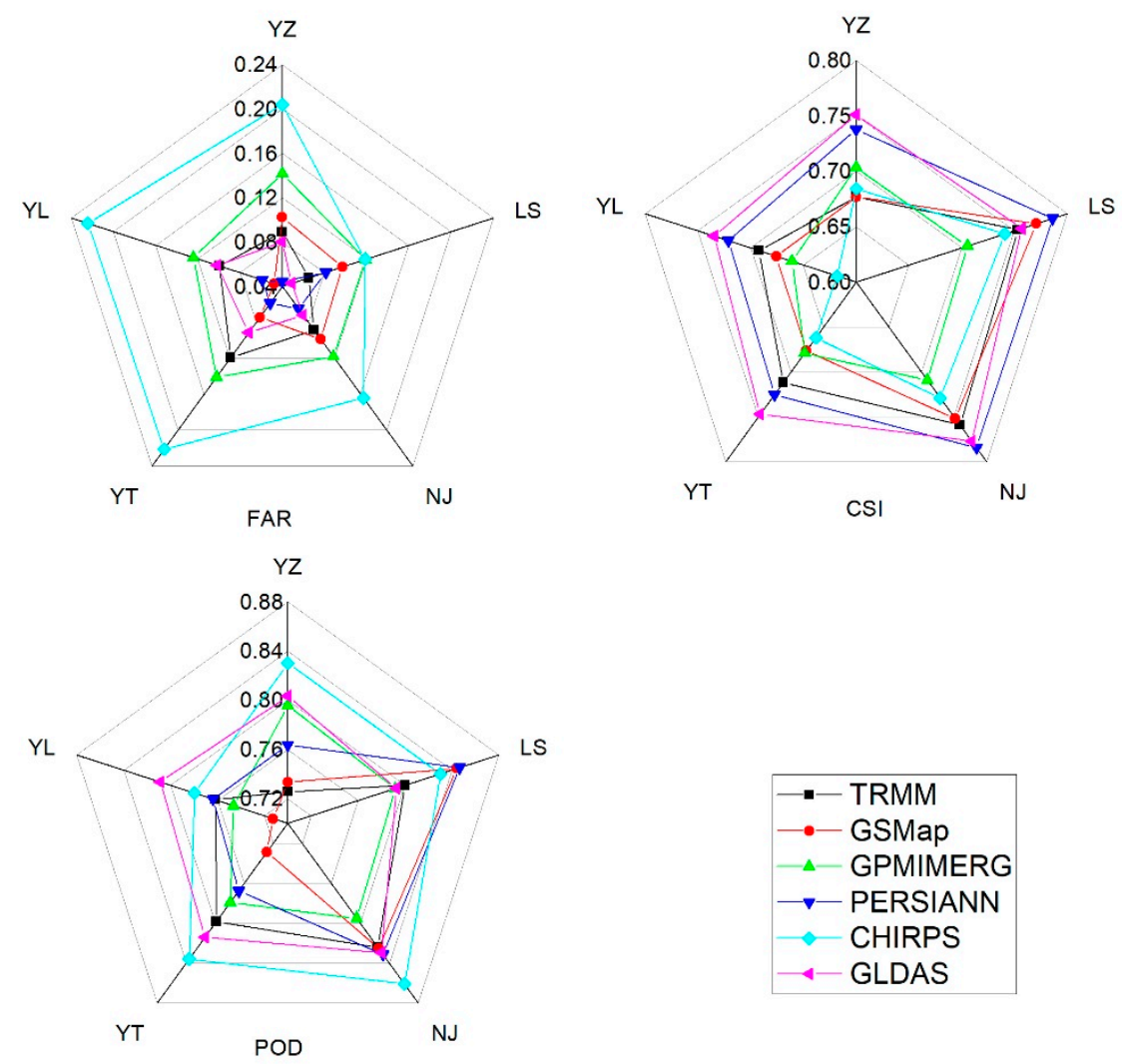

Figure 4. Classification analysis at the basin scale.

\subsection{Accuracy Evaluation of Satellite Precipitation Products at the Rain Gauge Scale}

In this study, we calculated the CC, bias, RMSE, and MAE for each rain gauge, and the results are drawn in Figures 5-8. In addition, we also calculated the POD, FAR, and CSI for each gauge (Figures 9-11). Then, we sorted the values of each product from the smallest to the largest and found the median value; the results are drawn in Figure 12.
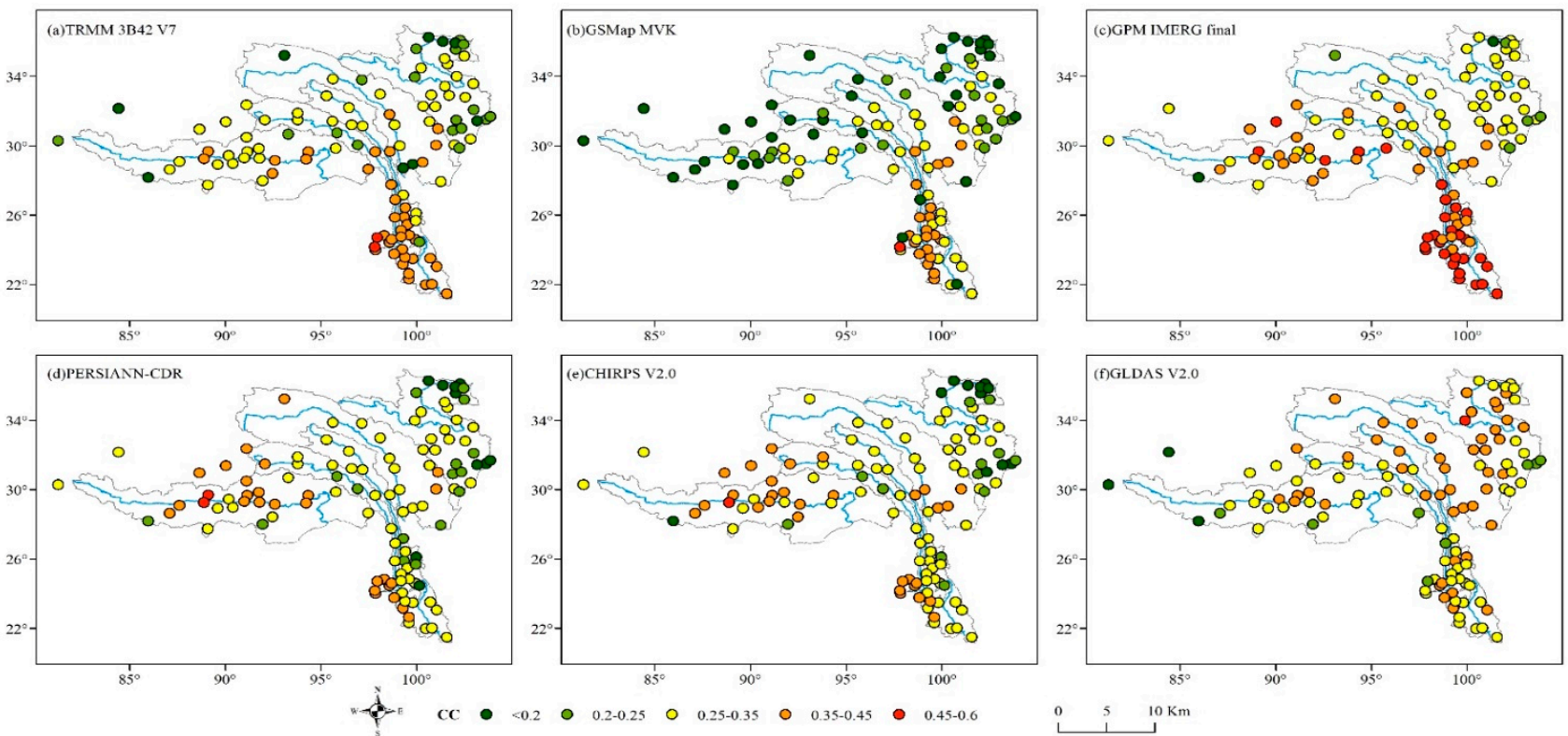

Figure 5. Correlation between different rain gauges and corresponding grids in data products. 

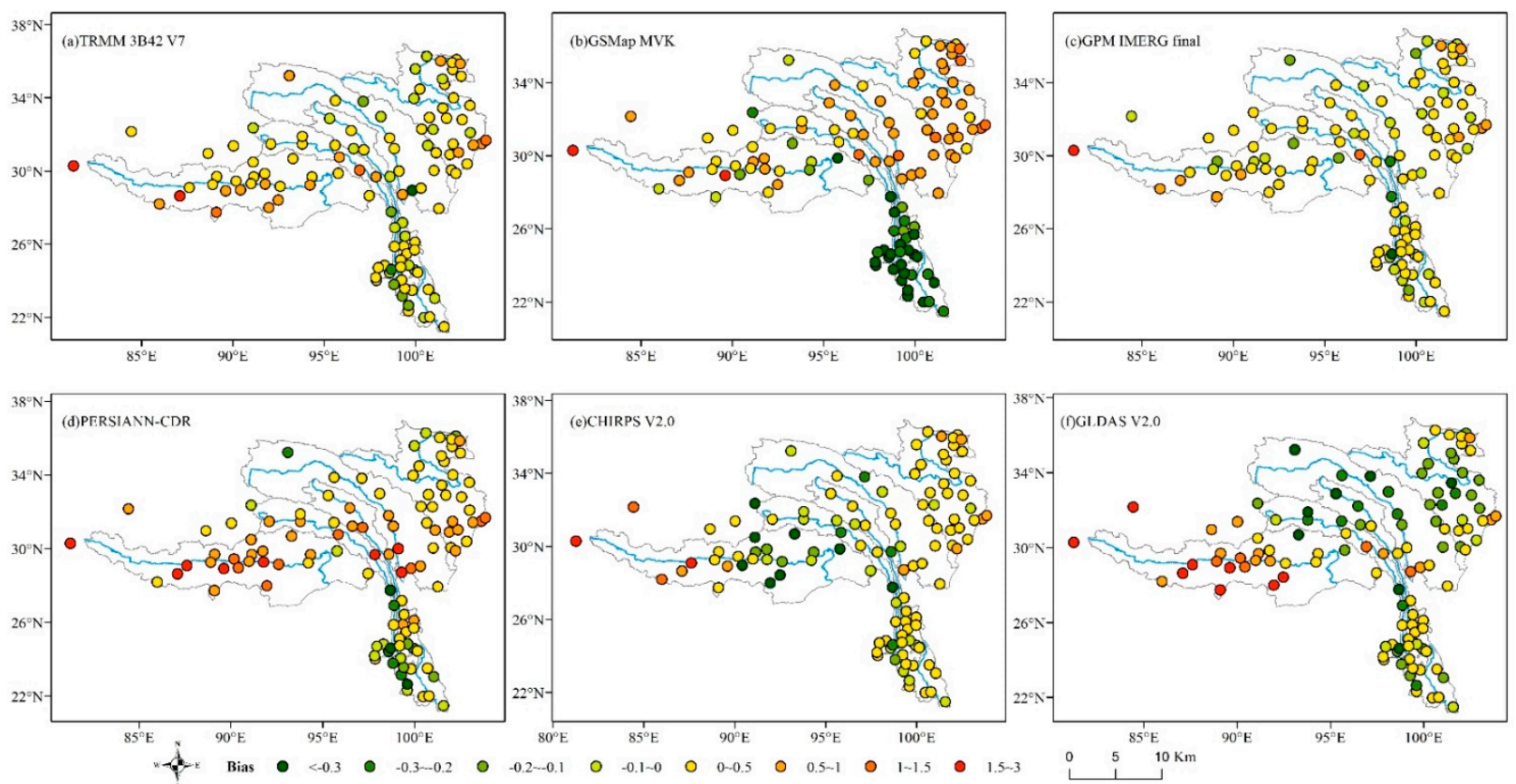

Figure 6. The degree of deviation between different rain gauges and corresponding grids in data products.
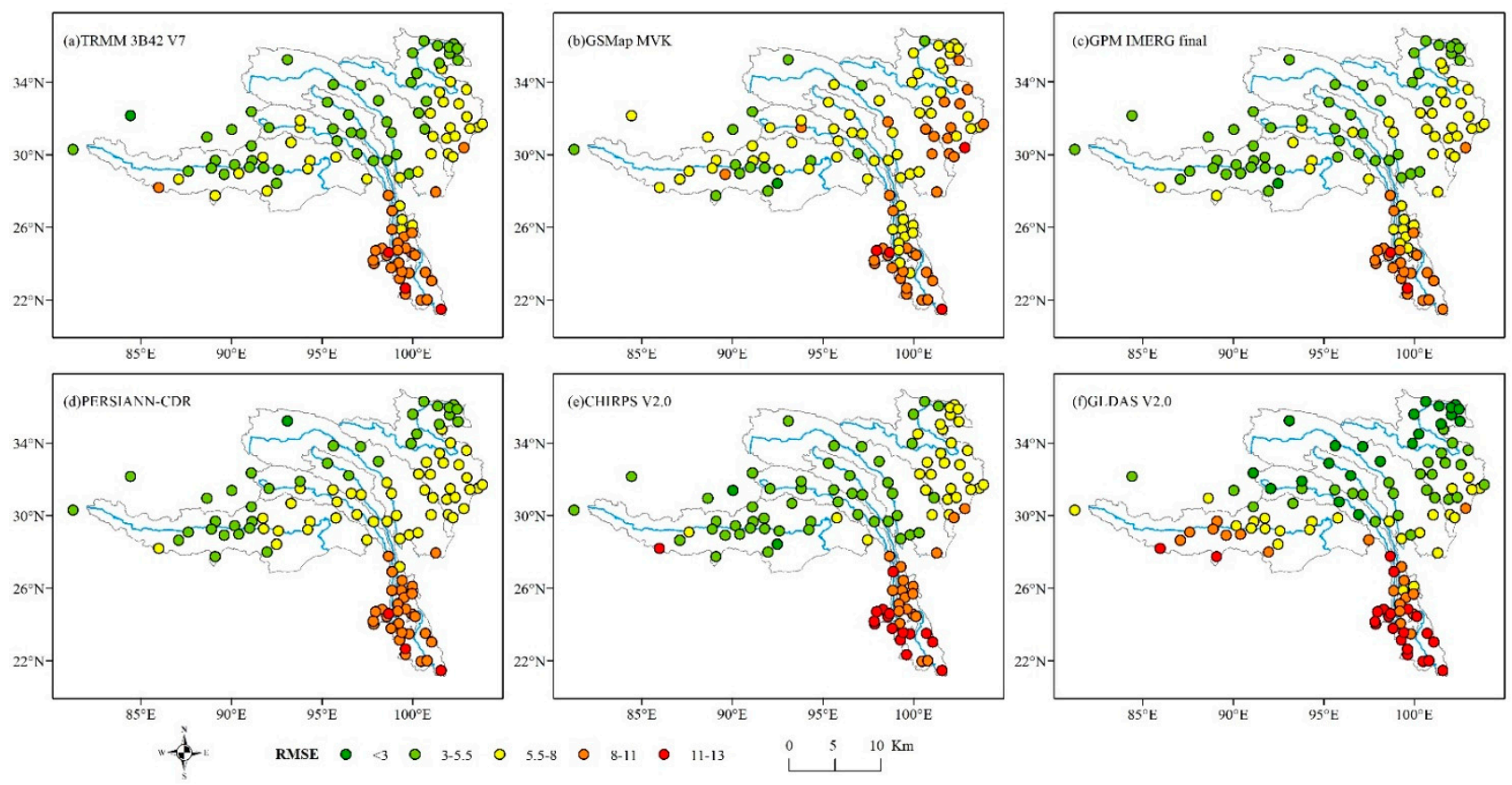

Figure 7. The RMSE between different rain gauges and corresponding grids in data products. 

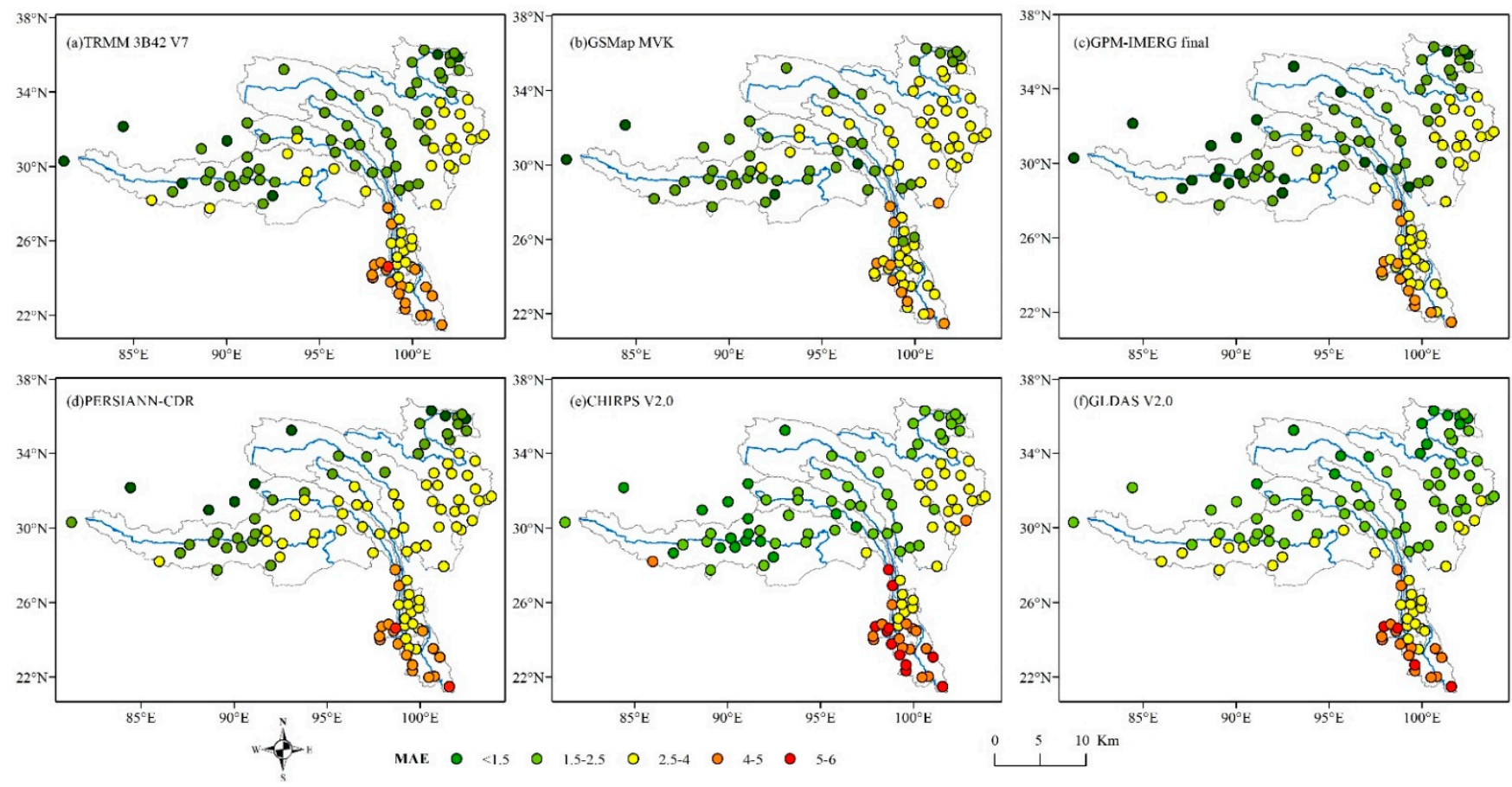

Figure 8. The MAE between different rain gauges and corresponding grids in data products.
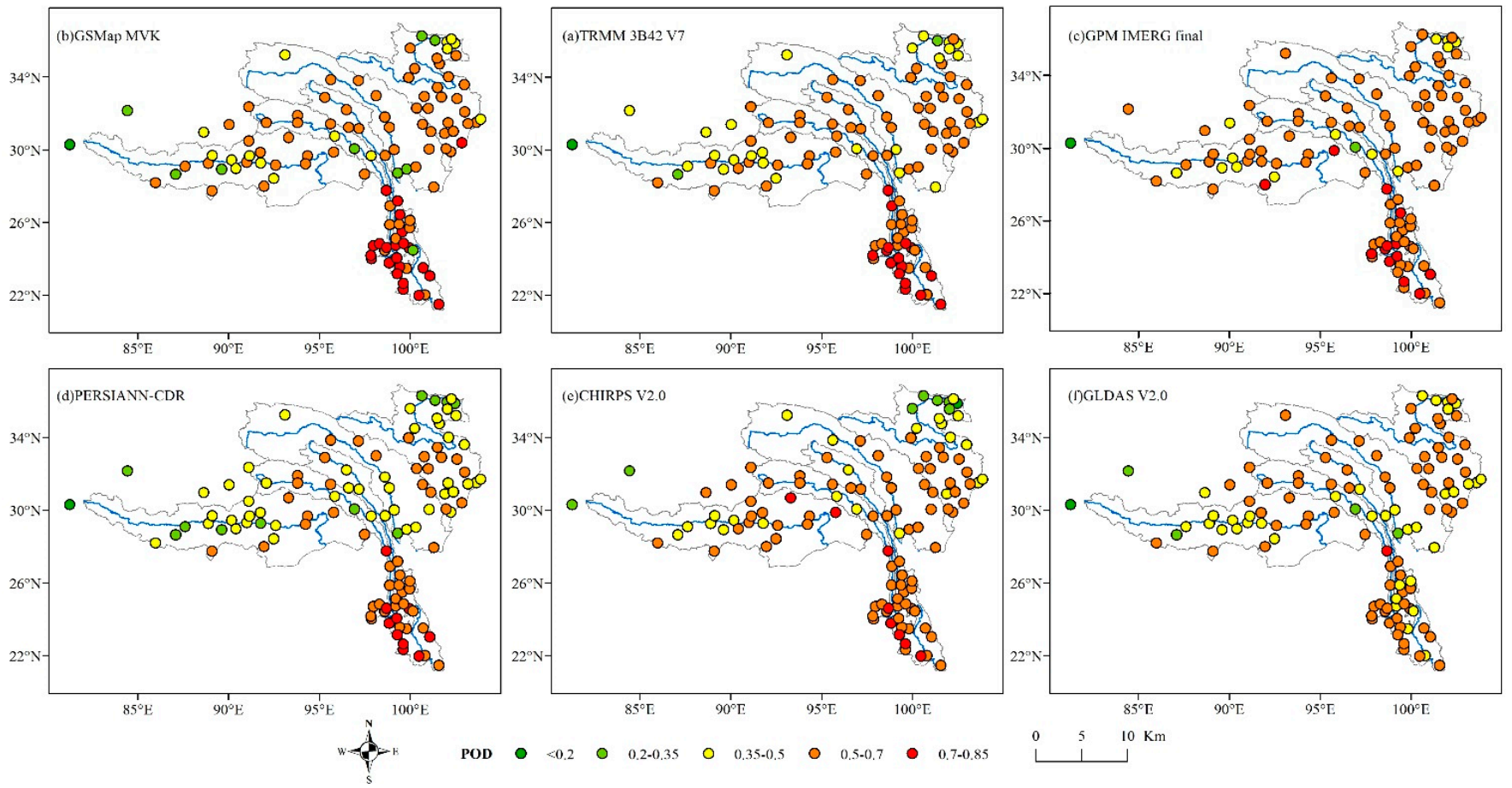

Figure 9. The POD between different rain gauges and corresponding grids in data products. 

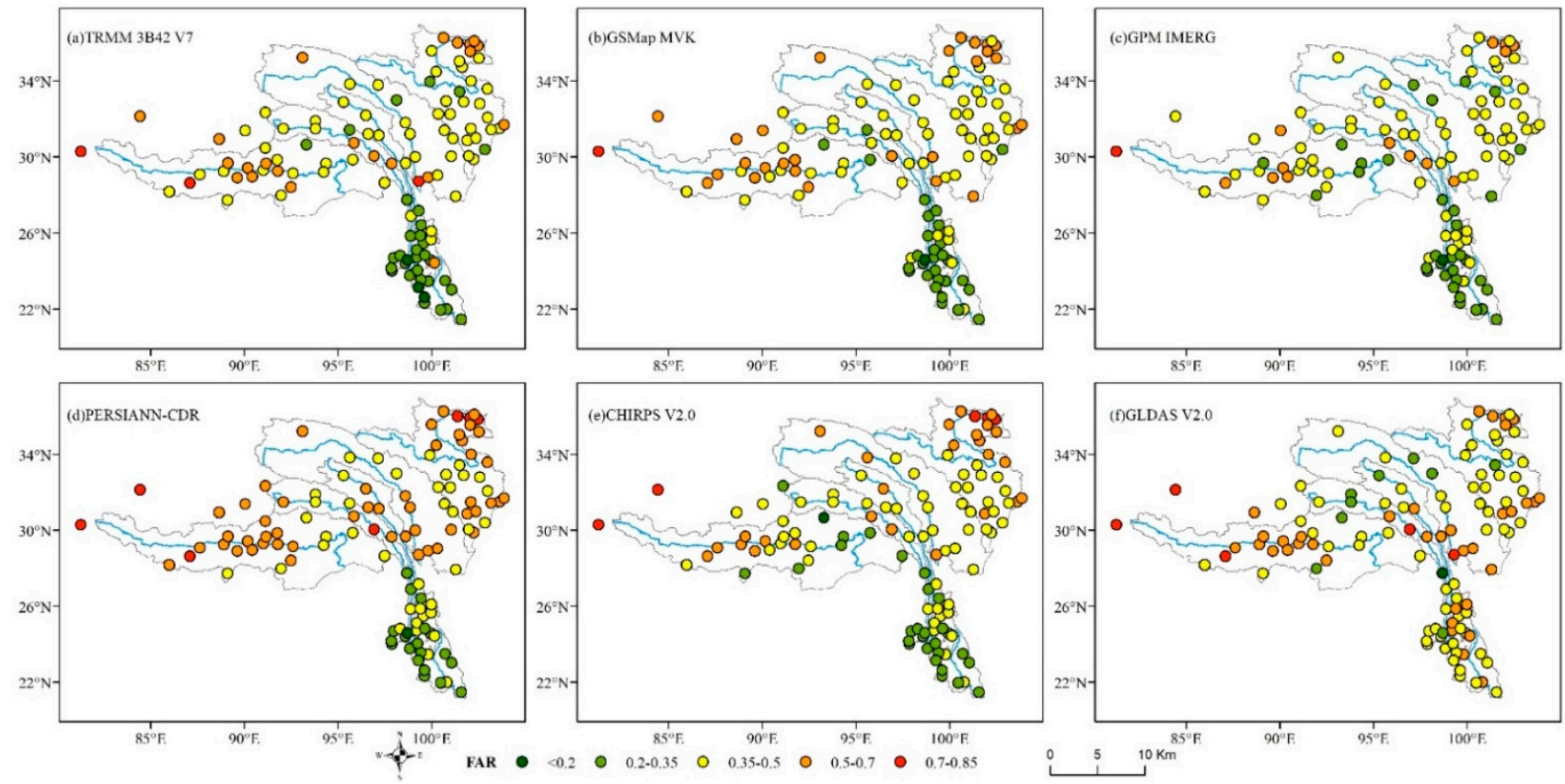

Figure 10. The FAR between different rain gauges and corresponding grids in data products.
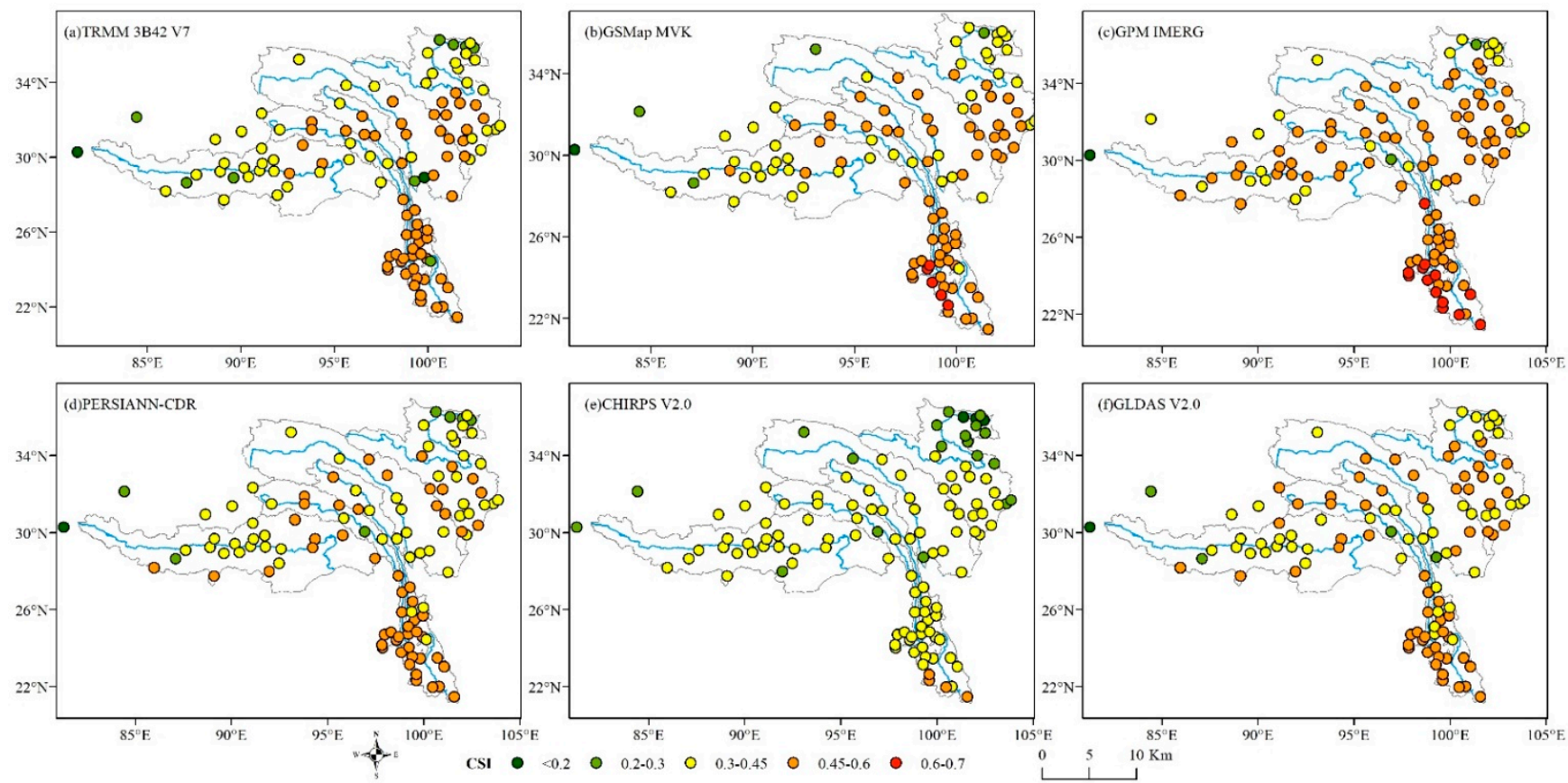

Figure 11. The CSI between different rain gauges and corresponding grids in data products.

We can clearly obtain the spatial distribution of each indicator through the evaluation at the rain gauge scale. On the whole, it is obvious that the CC, bias, POD, and FAR in the downstream regions of LS and NJ basins were better than those in other basins, but the RMSE and MAE were worse than those in other regions, mainly because this part is located in a humid region and the total precipitation is large. Meanwhile, we found that the RMSE and MAE of the six products decreased from southeast to northwest on the whole. 

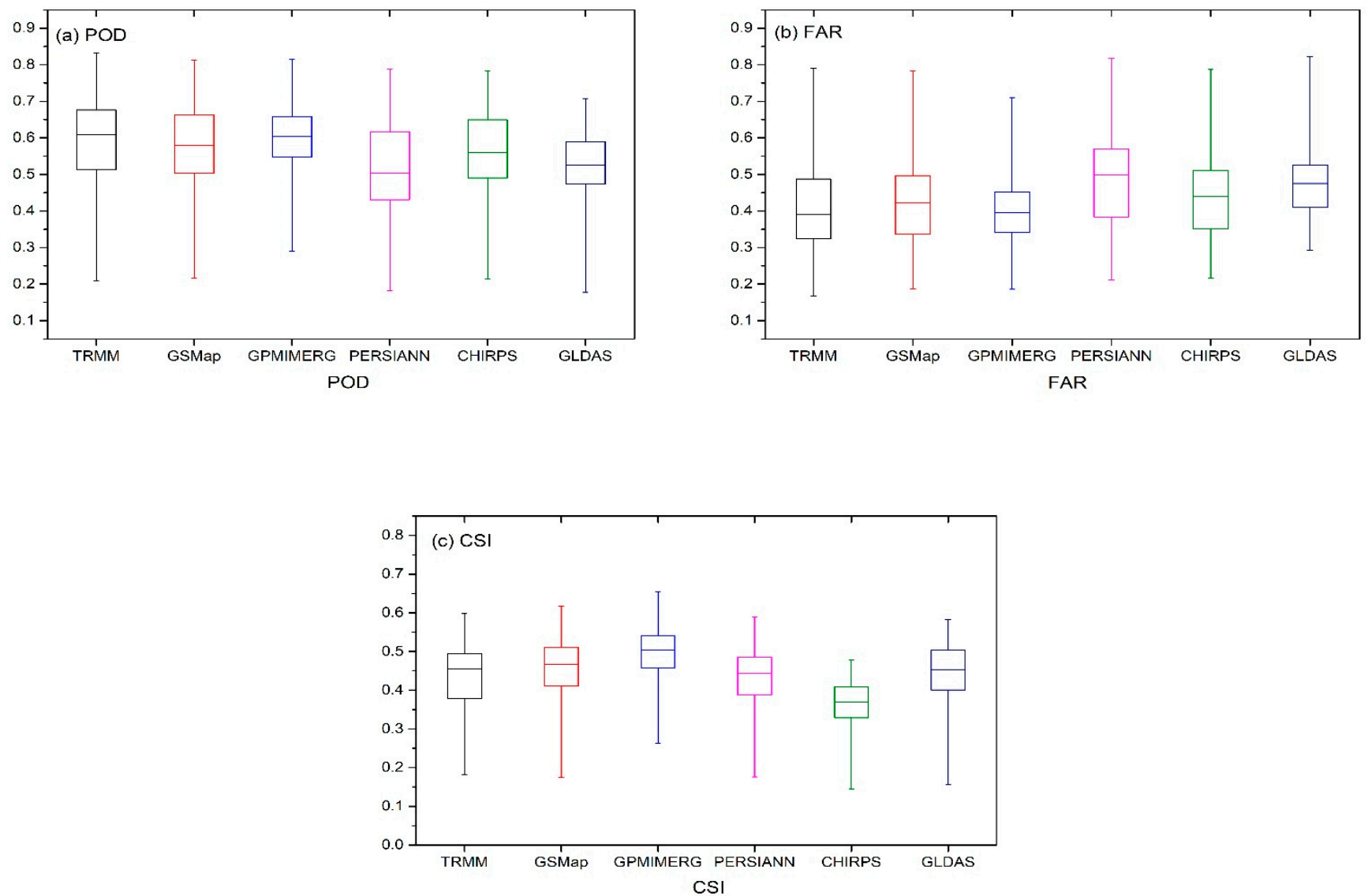

Figure 12. Classification index evaluation of six precipitation products. (a) represents the performance of POD of the six products, (b) represents the performance of FAR of the six products, (c) represents the performance of CSI of the six products. The line in the middle of the box represents the median value, each box ranges from the lower quartile (25th) to the upper quartile (75th), and the top and bottom lines represent the maximum and minimum values of each indicator, respectively.

We plotted the value of the POD, FAR, and CSI of all rain gauges into boxes (Figure 12). With regard to the FAR and CSI, it is obvious that GPM-IMERG Final performed better than other products, as the FAR of GPM-IMERG Final was the lowest among the six precipitation products (median FAR GPM IMERG Final $=0.396$ ), and the CSI of GPM-IMERG Final was the highest value among the six precipitation products (median CSI GPM IMERG Final $=0.504$ ). For the POD, GPM IMERG Final and TRMM 3B42 V7 both performed better than others (the median value of POD was 0.604 and 0.609 , respectively). The main reason for this phenomenon is that the sensor of GPM IMERG Final has stronger monitoring ability for weak precipitation and small water droplets; in addition, it integrates a variety of data inversion algorithms, which greatly improves its spatiotemporal accuracy.

For different river basins, GPM IMERG Final and CHIRPS V2.0 were recommended to the upper and middle reaches of the $Y Z$ basin, due to the good performance in this area, while the performance of the six products in the downstream region of the $Y Z$ basin was similar. The performance of GPM IMERG Final, TRMM 3B42 V7, CHIRPS V2.0, and GLDAS V2.0 in the upstream areas of LS and NJ basins was similar, and each of them performed well. However, due to the high bias of GSMaP MVK and PERSIANN-CDR, it was not recommended to use them in the upstream areas of LS and NJ. For YT and YR basins, the study area covered only the source part, so no further division was made. GLDAS V2.0 and GPM IMERG Final were recommended for YT and YR basins.

\subsection{Accuracy Evaluation of Satellite Precipitation Products in Elevation}

We plotted the distribution of the rain gauges in different elevations (Figure 1) and climate zones (Figure 2) and found that nearly $50 \%$ of the rain gauges are located at less 
than $3000 \mathrm{~m}$ altitude $(57 / 116)$ and approximately $21 \%$ of the stations $(25 / 117)$ are located above $4000 \mathrm{~m}$ altitude. Hence, we divided the stations into four categories according to the elevation to ensure that each elevation interval contained similar numbers of stations, and we divided the elevation interval into below $1500 \mathrm{~m}, 1500-3000 \mathrm{~m}, 3000-4000 \mathrm{~m}$, and above $4000 \mathrm{~m}$; there were $23,34,34$, and 25 gauges in these elevation intervals, respectively. At the same time, we found that nearly $50 \%$ of the rain gauges in the study area are located in the temperate climate zone, and with an increase in elevation, the climate zone changes from temperate zone to arid and then snowy.

It can be seen from the analysis of each elevation interval that the CC of GSMAP MVK showed a significant decrease with an increase in elevation, while other precipitation products showed a trend of decreasing with an increase in elevation when the elevation was less than $4000 \mathrm{~m}$, and then showed a slight increase when the elevation was higher than $4000 \mathrm{~m}$ (Table 6). With regard to bias (Table 7), TRMM 3B42 V7 and GLDAS V2.0 showed a significant increase with an increase in elevation. However, the bias of other precipitation products had no obvious relationship with elevation. It is worth mentioning that the bias of GPM IMERG Final at 3000-4000 m was 0.083 , nearly the lowest (bias $=0.074$ ) of four elevation intervals. It was similar to the conclusion of Ma et al. [2]. There may be two reasons for this: One is that the water vapor exchange rate in high-altitude regions is faster than that in low-altitude regions, which leads to a large vertical difference in precipitation. The other reason is that a high altitude is more likely to produce snowfall in winter, and satellite precipitation products are poor in the observation of snow [17,21]. For the RMSE and MAE (Figures 9 and 10), almost all data products showed a trend of decreasing as the elevation increased (Tables 8 and 9), which is mainly related to precipitation intensity [5]. This result was consistent with the conclusion of Chen et al. [5] and Gao et al. [17]. On this basis, we drew scatter distribution maps of elevation and the values of the RMSE and MAE and found that the values of RMSE and MAE of each of the six products decline most significantly at 3000-4000 $\mathrm{m}$ (Figures 13 and 14). The reasons for this phenomenon will be further explored in subsequent research. According to the performance of various indicators of different products, we believe that when the elevation is below $4000 \mathrm{~m}$, GPM IMERG Final and GLDAS V2.0 perform better, while when the elevation is above $4000 \mathrm{~m}$, GPM IMERG Final and CHIRPS V2.0 perform better.

Table 6. CC between different elevation intervals.

\begin{tabular}{ccccc}
\hline Precipitation Products & $\mathbf{< 1 5 0 0 ~} \mathbf{~}$ & $\mathbf{1 5 0 0} \mathbf{~} \mathbf{- 3 0 0 0} \mathbf{~}$ & $\mathbf{3 0 0 0} \mathbf{~} \mathbf{- 4 0 0 0} \mathbf{~}$ & $\mathbf{> 4 0 0 0} \mathbf{~ m}$ \\
\hline TRMM 3B42 V7 & 0.690 & 0.653 & 0.616 & 0.647 \\
GPM IMERG & 0.749 & 0.718 & 0.545 & 0.733 \\
GSMAP MVK & 0.618 & 0.564 & 0.749 & 0.511 \\
GLDAS V2.0 & 0.623 & 0.657 & 0.562 & 0.734 \\
PERSIANN-CDR & 0.592 & 0.540 & 0.539 & 0.666 \\
CHIRPS V2.0 & 0.622 & 0.584 & 0.675 \\
\hline
\end{tabular}

Table 7. Bias between different elevation intervals.

\begin{tabular}{|c|c|c|c|c|}
\hline Precipitation Products & $<1500 \mathrm{~m}$ & $1500 \mathrm{~m}-3000 \mathrm{~m}$ & $3000 \mathrm{~m}-4000 \mathrm{~m}$ & $>4000 \mathrm{~m}$ \\
\hline TRMM 3B42 V7 & 0.044 & 0.156 & 0.171 & 0.343 \\
\hline GPM IMERG & 0.074 & 0.110 & 0.083 & 0.198 \\
\hline GSMAP MVK & -0.331 & 0.149 & 0.599 & 0.168 \\
\hline GLDAS V2.0 & -0.014 & 0.080 & 0.099 & 0.487 \\
\hline PERSIANN-CDR & -0.051 & 0.254 & 0.644 & 0.621 \\
\hline CHIRPS V2.0 & 0.099 & 0.133 & 0.038 & 0.159 \\
\hline
\end{tabular}


Table 8. RMSE between different elevation intervals.

\begin{tabular}{ccccc}
\hline Precipitation Products & $\mathbf{< 1 5 0 0 ~} \mathbf{~}$ & $\mathbf{1 5 0 0} \mathbf{~} \mathbf{- 3 0 0 0} \mathbf{~ m}$ & $\mathbf{3 0 0 0} \mathbf{~} \mathbf{- 4 0 0 0} \mathbf{~ m}$ & $\mathbf{> 4 0 0 0} \mathbf{~ m}$ \\
\hline TRMM 3B42 V7 & 4.106 & 2.436 & 2.067 & 1.762 \\
GPM IMERG & 3.769 & 2.156 & 2.746 & 1.403 \\
GSMAP MVK & 4.199 & 2.672 & 1.573 & 1.703 \\
GLDAS V2.0 & 4.046 & 2.174 & 3.102 & 1.864 \\
PERSIANN-CDR & 4.591 & 3.167 & 2.261 & 2.221 \\
CHIRPS V2.0 & 5.157 & 2.944 & & 1.624 \\
\hline
\end{tabular}

Table 9. MAE between different elevation intervals.

\begin{tabular}{ccccc}
\hline Precipitation Products & $\mathbf{< 1 5 0 0 ~} \mathbf{~}$ & $\mathbf{1 5 0 0} \mathbf{~} \mathbf{- 3 0 0 0} \mathbf{~}$ & $\mathbf{3 0 0 0} \mathbf{~} \mathbf{- 4 0 0 0} \mathbf{~ m}$ & $\mathbf{> 4 0 0 0} \mathbf{~ m}$ \\
\hline TRMM 3B42 V7 & 2.251 & 1.429 & 1.184 & 1.031 \\
GPM IMERG & 2.099 & 1.254 & 1.652 & 0.829 \\
GSMAP MVK & 2.296 & 1.605 & 0.880 & 1.068 \\
GLDAS V2.0 & 2.340 & 1.312 & 1.715 & 0.992 \\
PERSIANN-CDR & 2.528 & 1.791 & 1.270 & 1.248 \\
CHIRPS V2.0 & 2.763 & 1.673 & 0.940 \\
\hline
\end{tabular}

(a) TRMM 3B42 V7

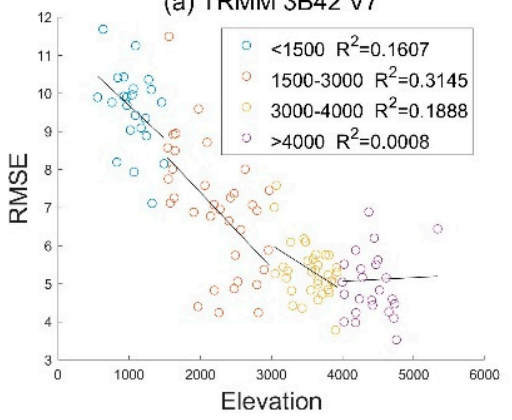

(d) PERSIANN-CDR

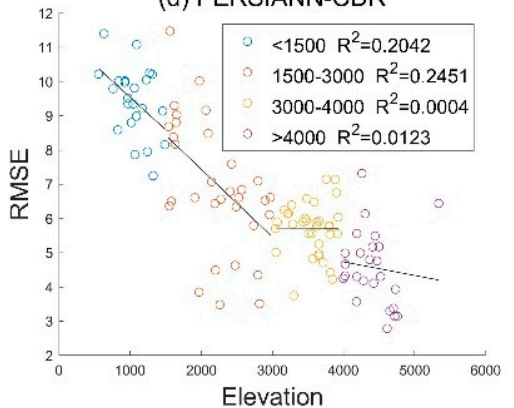

(b) GSMaP MVK

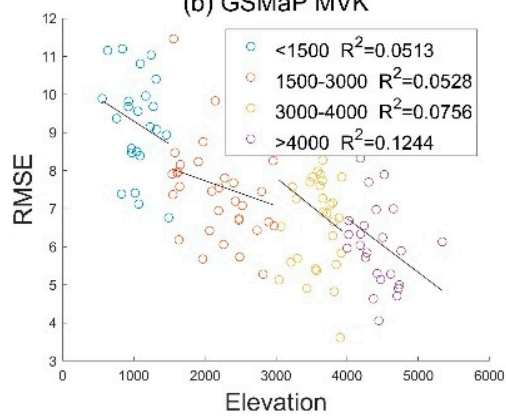

(e) CHIRPS V2.0

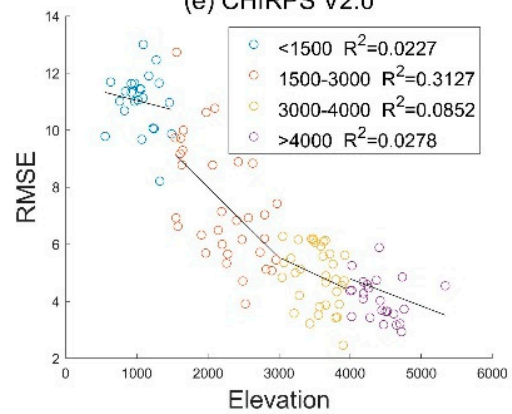

(c) GPM IMERG final

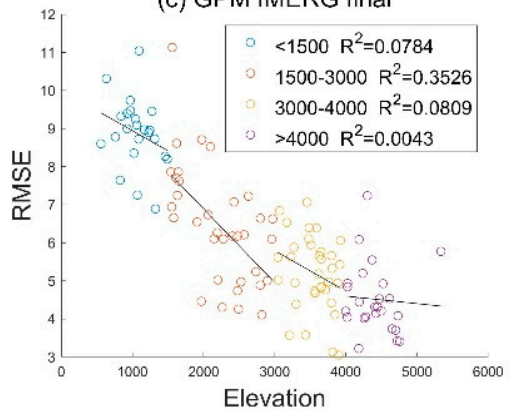

(f) GLDAS V2.0

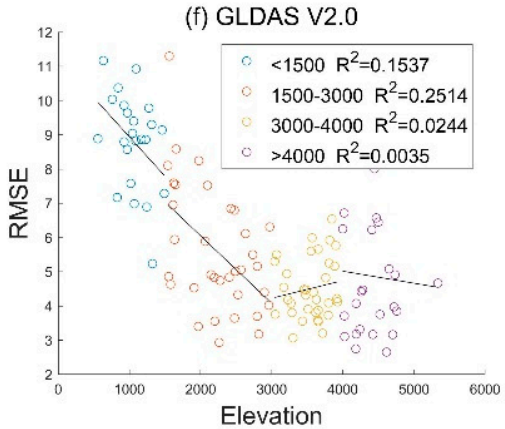

Figure 13. Linear relationship between RMSE and elevation. (a) Represents the trend of RMSE and Elevation for TRMM $3 B 42$ V7 data products with elevation changes; (b) Represents the trend of RMSE and Elevation for GSMaP MVK data products with elevation changes; (c) Represents the trend of RMSE and Elevation for GPM IMERG final data products with elevation changes; (d) Represents the trend of RMSE and Elevation for PERSIANN-CDR data products with elevation changes; (e) Represents the trend of RMSE and Elevation for CHIRPS V2.0 data products with elevation changes; (f) Represents the trend of RMSE and Elevation for GLDAS V2.0 data products with elevation changes. 

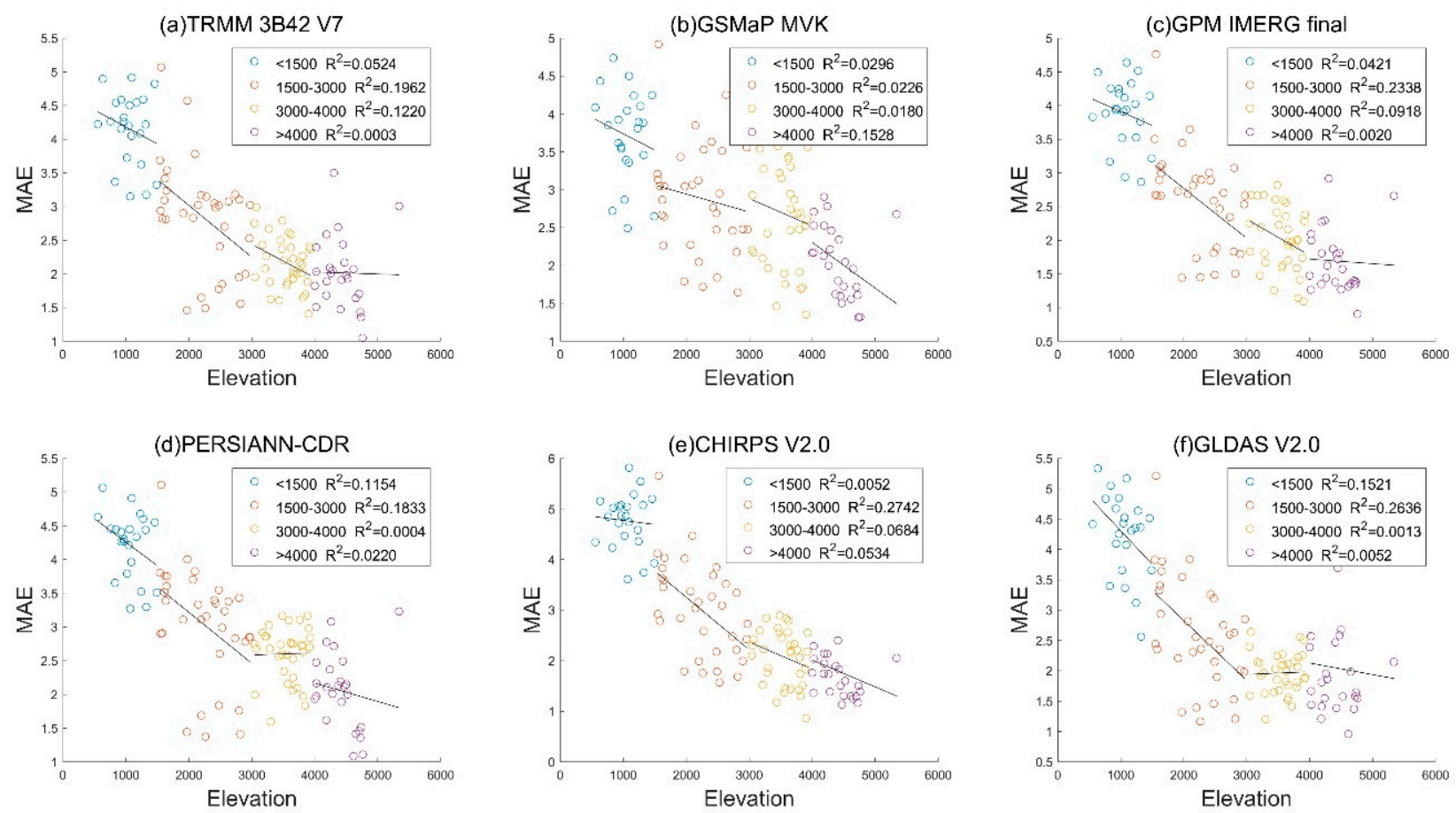

Figure 14. Linear relationship between MAE and elevation. (a) Represents the trend of MAE and Elevation for TRMM 3B42 V7 data products with elevation changes; (b) Represents the trend of MAE and Elevation for GSMaP MVK data products with elevation changes; (c) Represents the trend of MAE and Elevation for GPM IMERG final data products with elevation changes; (d) Represents the trend of MAE and Elevation for PERSIANN-CDR data products with elevation changes; (e) Represents the trend of MAE and Elevation for CHIRPS V2.0 data products with elevation changes; (f) Represents the trend of MAE and Elevation for GLDAS V2.0 data products with elevation changes.

\section{Conclusions}

In this study, six kinds of daily-scale precipitation products (TRMM 3B42 V7, GSMAP MVK, GPM IMERG Final, PERSIANN-CDR, CHIRPS V2.0, and GLDAS V2.0) were systematically evaluated by combining quantitative evaluation and classification evaluation; the time series of the study was 2001-2019. During analysis of the results, we also considered the effects of elevation and climate on the evaluation indicators, and the conclusions were mainly as follows:

1. The six precipitation products can accurately monitor the occurrence of precipitation events in the five river basins. According to the performance analysis of the mentioned products, GPM IMERG Final and CHIRPS V2.0 are recommended for the YZ basin, while GPM IMERG Final and GLDAS V2.0 are recommended for the other four basins.

2. There are some differences in the spatial distribution of indicators of the six products. For the upstream and middle reaches of $Y Z$, we prefer to recommend GPM IMERG Final and CHIRPS V2.0; for the downstream reach of $Y Z$, all six products can perform well. For the upstream reaches of LS and NJ, GPM IMERG Final, TRMM 3B42 V7, CHIRPS V2.0, and GLDAS V2.0 can be recommended, as for other basins, the products we recommend are the same as conclusion 1 .

3. According to the analysis results of quantitative indexes in different elevation intervals, we prefer to recommend GPM IMERG Final and GLDAS V2.0 when elevation is below $4000 \mathrm{~m}$, and GPM IMERG Final and CHIRPS V2.0 are recommended when elevation is above $4000 \mathrm{~m}$.

Overall, this study evaluated the performance of six precipitation products in different basins in southwest China. The advantage of this study was that the study area was located in the TP, and the YGP, with large elevation changes, is the birthplace of many rivers and is located in multiple climatic zones; it is representative for the accuracy assessment 
of precipitation products in different watersheds, different elevation intervals, and even different climatic regions. This study evaluated the accuracy of precipitation products using statistical methods and also evaluated the ability to monitor precipitation events through classification analysis; this method can objectively evaluate the accuracy of precipitation products. The evaluation method in this paper is not only applicable to this area but also applicable to other areas. In addition, it is worth noting that due to the complex topography of the study area, the results may not be applicable to all basins. The performance of GPM IMERG Final in this study was better than other precipitation products in all basins, which provides a guiding value for multi-source monitoring fusion and multi-source algorithm fusion of data products. At the same time, the analysis of error and elevation also provides a reference for data product developers to improve the accuracy of products. The future expansion of this study can be divided into two parts: one is the research of the assimilation and fusion algorithm of multi-source heterogeneous precipitation data; the other is the evaluation of multi-source heterogeneous data in the hydrologic application, which may provide strong data support for hydro-meteorologists in the sparse area of gauges.

Author Contributions: Methodology, X.J. and Y.L.; software, T.L.; validation, X.J. and P.G.; formal analysis, X.J., Y.L., and Y.W.; investigation, G.W.; data curation, X.J. and X.Z.; writing-original draft preparation, X.J.; writing-review and editing, Y.L.; visualization, Q.M.; supervision, Y.W.; project administration, Y.W. All authors have read and agreed to the published version of the manuscript.

Funding: This research was funded by the National Key Research and Development Program of China (No.2016YFA0601703) and the National Natural Science Foundation of China (No. 91847301; 92047203; 52009080).

Institutional Review Board Statement: Not applicable.

Informed Consent Statement: Not applicable.

Data Availability Statement: All the data involved in this article can be downloaded and used through the links provided in the article.

Acknowledgments: The authors would like to express their sincere thanks to all the anonymous reviewers and editors for their comments on this paper, which have helped to make it more structured and informative.

Conflicts of Interest: The authors of this paper declare that there is no conflict of interest.

\section{References}

1. Alijanian, M.; Rakhshandehroo, G.R. Evaluation of satellite rainfall climatology using CMORPH, PERSIANN-CDR, PERSIANN, TRMM, MSWEP over Iran. Int. J. Climatol. 2017, 37, 4896-4914. [CrossRef]

2. Ma, L.; Zhao, L. Evaluation of the integrated multi-satellite retrievals for global precipitation measurement over the Tibetan Plateau. J. Mt. Sci.-Engl. 2019, 16, 1500-1514. [CrossRef]

3. Ur Rahman, K.; Shang, S. An Appraisal of Dynamic Bayesian Model Averaging-based Merged Multi-Satellite Precipitation Datasets Over Complex Topography and the Diverse Climate of Pakistan. Remote Sens. 2020, 12, 10. [CrossRef]

4. Abd Elhamid, A.M.I.; Eltahan, A.M.H. Assessment of the two satellite-based precipitation products TRMM and RFE rainfall records using ground based measurements. Alex. Eng. J. 2020, 59, 1049-1058. [CrossRef]

5. Chen, H.; Yong, B. Comparison Analysis of Six Purely Satellite-derived Global Precipitation Estimates. J. Hydrol. 2019, 581, 124376. [CrossRef]

6. Liu, S.; Yan, D. Correction of TRMM 3B42V7 Based on Linear Regression Models over China. Adv. Meteorol. 2016, 2016, 3103749. [CrossRef]

7. Xiang, Y.; Chen, J. Evaluation of Eight Global Precipitation Datasets in Hydrological Modeling. Remote Sens. 2021, $13,2831$. [CrossRef]

8. Abdelmoneim, H.; Soliman, M.R.; Moghazy, H.M. Evaluation of TRMM 3B42V7 and CHIRPS Satellite Precipitation Products as an Input for Hydrological Model over Eastern Nile Basin. Earth Syst. Environ. 2020, 4, 685-698. [CrossRef]

9. Lu, Y.; Yang, S. The Applicability Analysis of TRMM Precipitation Data in the Yarlung Zangbo River Basin. J. Nat. Resour. 2013, 8, 1414-1425.

10. Jiang, S.; Ren, L. Hydrological evaluation of the TRMM multi-satellite precipitation estimates over the Mishui basin. Adv. Water Sci. 2014, 25, 641-649. 
11. Franchito, S.H.; Rao, V.B.; Vasques, A.C. Validation of TRMM precipitation radar monthly rainfall estimates over Brazil. J. Geophys. Res. 2009, 114, D02105. [CrossRef]

12. Yang, M.; Liu, G.; Chen, T. Evaluation of GPM IMERG precipitation products with the point rain gauge records over Sichuan, China. Atmos. Res. 2019, 246, 105101. [CrossRef]

13. Li, Z. Multi-Source Precipitation Observations and Fusion for Hydrological Applications in the Yangtze River Basin. Ph.D. Thesis, Tsinghua University, Beijing, China, 2015.

14. Wang, Z.; Zhong, R. Evaluation of TRMM 3B42-V7 satellite-based precipitation data product in the Pearl River basin, China: Dong jiang River and Beijiang River basin as examples. Adv. Water Sci. 2017, 28, 174-182.

15. Bharti, V.; Singh, C. Evaluation of error in TRMM 3B42V7 precipitation estimates over the Himalayan region. J. Geophys. Res. Atmos. 2015, 120, 12458-12473. [CrossRef]

16. Funk, C.; Peterson, P.; Landsfeld, M. The climate hazards infrared precipitation with stations-a new environmental record for monitoring extremes. Sci. Data 2015, 2, 150066. [CrossRef]

17. Gao, Y.C.; Liu, M.F. Evaluation of high-resolution satellite precipitation products using rain gauge observations over the Tibetan Plateau. Hydrol. Earth Syst. Sc. 2013, 17, 837-849. [CrossRef]

18. Ahmed, E.; Al Janabi, F.; Zhang, J. Hydrologic Assessment of TRMM and GPM-Based Precipitation Products in Transboundary River Catchment (Chenab River, Pakistan). Water-Sui. 2020, 12, 1902. [CrossRef]

19. Sun, H.; Su, F. Evaluation of multiple precipitation datasets and their potential utilities in hydrologic modeling over the Yarlung Zangbo River Basin. Prog. Geogr. 2020, 39, 1126-1139. [CrossRef]

20. Sungmin, O.; Foelsche, U.; Kirchengast, G. Evaluation of GPM IMERG Early, Late, and Final rainfall estimates using WegenerNet gauge data in southeastern Austria. Hydrol. Earth Syst. Sc. 2017, 21, 6559-6572.

21. Derin, Y.; Anagnostou, E.; Berne, A. Multiregional Satellite Precipitation Products Evaluation over Complex Terrain. J. Hydrometeorol. 2016, 17, 1817-1836. [CrossRef]

22. $\mathrm{Hu}, \mathrm{Q}$. Rainfall Spatial Estimation Using Multi-Source Information and Its Hydrological Application. Ph.D. Thesis, Tsinghua University, Beijing, China, 2013.

23. Xu, R.; Tian, F.; Yang, L. Ground validation of GPM IMERG and TRMM 3B42V7 rainfall products over southern Tibetan Plateau based on a high-density rain gauge network. J. Geophys. Res. Atmos. 2017, 122, 910-924. [CrossRef]

24. Tan, X.; Ma, Z.; He, K. Evaluations on gridded precipitation products spanning more than half a century over the Tibetan Plateau and its surroundings. J. Hydrol. 2020, 582, 124455. [CrossRef]

25. Tong, K.; Su, F.; Yang, D. Tibetan Plateau precipitation as depicted by gauge observations, reanalyses and satellite retrievals. Int. J. Climatol. 2014, 34, 265-285. [CrossRef]

26. Li, G.; Yu, Z.; Wang, W. Analysis of the spatial Distribution of precipitation and topography with GPM data in the Tibetan Plateau. Atmos. Res. 2021, 247, 105259. [CrossRef]

27. Kubota, T.; Shige, S. Global Precipitation Map Using Satellite-Borne Microwave Radiometers by the GSMaP Project: Production and Validation. IEEE Trans. Geosci. Remote 2007, 45, 2259-2275. [CrossRef]

28. Ushio, T.; Sasashige, K.; Kubota, T. A Kalman Filter Approach to the Global Satellite Mapping of Precipitation (GSMaP) from Combined Passive Microwave and Infrared Radiometric Data. J. Meteorol. Soc. Jpn. Ser. II 2009, 87A, 137-151. [CrossRef]

29. Fu, Q.; Ruan, R.; Liu, Y. Accuracy Assessment of Global Satellite Mapping of Precipitation (GSMaP) Product over Poyang Lake Basin, China. Procedia Environ. Sci. 2011, 10, 2265-2271. [CrossRef]

30. Ramsauer, T.; Wei, T.; Marzahn, P. Comparison of the GPM IMERG Final Precipitation Product to RADOLAN Weather Radar Data over the Topographically and Climatically Diverse Germany. Remote Sens. 2018, 10, 2029. [CrossRef]

31. Hamed, A.; Kuo-Lin, H.; Soroosh, S. PERSIANN-CDR: Daily Precipitation Climate Data Record from Multi-Satellite 2 Observations for Hydrological and Climate Studies. Am. Meteorol. Soc. 2014, 96, 69-83. [CrossRef]

32. Tan, M.L.; Santo, H. Comparison of GPM IMERG, TMPA 3B42 and PERSIANN-CDR satellite precipitation products over Malaysia. Atmos. Res. 2018, 202, 63-76. [CrossRef]

33. Katsanos, D.; Retalis, A.; Michaelides, S. Validation of a high-resolution precipitation database (CHIRPS) over Cyprus for a 30-year period. Atmos. Res. 2016, 169, 459-464. [CrossRef]

34. Shen, Z.; Yong, B.; Gourley, J.J. Recent global performance of the Climate Hazards group Infrared Precipitation (CHIRP) with Stations (CHIRPS). J. Hydrol. 2020, 591, 125284. [CrossRef]

35. Zhang, H.; Zhang, L.; Li, J. Climate and Hydrological Change Characteristics and Applicability of GLDAS Data in the Yarlung Zangbo River Basin, China. Water-Sui 2018, 10, 254. [CrossRef]

36. Li, X.; Gao, Y.; Wang, W. Climate changes and applicability of GLDAS in the headwater of the Yellow River Basin. Adv. Earth Sci. 2014, 29, 531-540.

37. Huang, X.; Wang, Z.G.; Sang, Y.F. Precision of data in three precipitation datasets of the Yarlung Zangbo River Basin. Progress Geogr. 2016, 35, 339-348.

38. Dilinuer, T.; Yao, J.; Chen, J. Regional drying and wetting trends over Central Asia based on Köppen climate classification in 1961-2015. Adv. Clim. Chang. Res. 2021, 12, 363-372. [CrossRef]

39. Chen, D.; Chen, H.W. Using the Köppen classification to quantify climate variation and change: An example for 1901-2010. Environ. Dev. 2013, 6, 69-79. [CrossRef] 
40. Liu, J.; Xu, Z.; Zhao, H. Accuracy assessment for two satellite precipitation products: Case studies in the Yarlung Zangbo River Basin. Plateau Meteorol. 2019, 38, 386-396.

41. Meng, Q.; Liu, Y.; Ju, Q. Analysis of temporal and spatial distribution characteristics of precipitation based on muli-source data assimilation and fusion in Niyang River Basin. South North Water Transf. Water Sci. Technol. 2020, 18, 110-118.

42. Ren, Z.; Zhao, P.; Zhang, Q. Quality control procedures for hourly precipitation data from automatic weather stations in China. Meteorol. Mon. 2010, 36, 123-132. (In Chinese) 